\title{
Liquidity Effect in OTC Options Markets: Premium or Discount?
}

\author{
PRACHI DEUSKAR ${ }^{1}$
}

ANURAG GUPTA ${ }^{2}$

MARTI G. SUBRAHMANYAM ${ }^{3}$

February 2010

\begin{abstract}
Can the liquidity premium in asset prices, as documented in the exchange-traded equity and bond markets, be generalized to the over-thecounter (OTC) derivative markets? Using OTC euro $(€)$ interest rate cap and floor data, we find that illiquid options trade at higher prices relative to liquid options. This liquidity discount, though opposite to that found in equities and bonds, is consistent with the structure of this OTC market and the nature of its demand and supply forces. Our results suggest that the effect of liquidity on asset prices cannot be generalized without regard to the characteristics of the market.
\end{abstract}

JEL Classification: G10, G12, G13, G15

Keywords: Liquidity, interest rate options, euro interest rate markets, Euribor market, OTC options markets.

\footnotetext{
${ }^{1}$ Department of Finance, College of Business, University of Illinois at Urbana-Champaign, 340 Wohlers Hall, 1206 S Sixth St, Champaign, IL 61820. Ph: (217) 244-0604, E-mail: pdeuskar@illinois.edu.

2 Department of Banking and Finance, Weatherhead School of Management, Case Western Reserve University, 10900 Euclid Avenue, Cleveland, Ohio 44106-7235. Ph: (216) 368-2938, Fax: (216) 3686249, E-mail: anurag@case.edu.

${ }^{3}$ Department of Finance, Leonard N. Stern School of Business, New York University, 44 West Fourth Street \#9-15, New York, NY 10012-1126. Ph: (212) 998-0348, Fax: (212) 995-4233, E-mail: msubrahm@stern.nyu.edu.

"We thank Viral Acharya, Yakov Amihud, Menachem Brenner, Jefferson Duarte, Apoorva Koticha, Haitao Li, Neil Pearson, George Pennacchi, Allen Poteshman, Peter Ritchken, Matt Spiegel, Kent Womack, and the participants at the Bank of Canada conference on fixed income markets, the 2007 European Finance Association meetings, the $7^{\text {th }}$ FDIC/JFSR conference on liquidity and liquidity risk, the 2008 China International Conference in Finance, and the International Conference on Price, Liquidity and Credit Risks in Konstanz, 2008, for suggestions and helpful discussions on this paper. We also thank an anonymous referee for useful comments, and the editor, Eugene Kandel, for excellent editorial inputs, both of which improved the paper a great deal. We remain responsible for all errors.
} 


\title{
Liquidity Effect in OTC Options Markets: Premium or Discount?
}

\author{
February 2010
}

\begin{abstract}
Can the liquidity premium in asset prices, as documented in the exchange-traded equity and bond markets, be generalized to the over-thecounter (OTC) derivative markets? Using OTC euro $(€)$ interest rate cap and floor data, we find that illiquid options trade at higher prices relative to liquid options. This liquidity discount, though opposite to that found in equities and bonds, is consistent with the structure of this OTC market and the nature of its demand and supply forces. Our results suggest that the effect of liquidity on asset prices cannot be generalized without regard to the characteristics of the market.
\end{abstract}

JEL Classification: G10, G12, G13, G15

Keywords: Liquidity, interest rate options, euro interest rate markets, Euribor market, OTC options markets. 
SINCE THE SEMINAL PAPER by Amihud and Mendelson (1986), numerous theoretical and empirical studies in equity and fixed income markets have shown that stocks and bonds with lower liquidity have lower prices and command higher expected returns. ${ }^{4}$ However, relatively little is known about the implications of liquidity for pricing in derivatives markets, such as those for equity or interest rate options. An exception in this relatively sparse literature is the study by Brenner et al. (2001), who confirm the normally expected result that non-tradable currency options in Israel are discounted by 21 percent on average, as compared to exchange-traded options. ${ }^{5}$ But is this always the case, especially for over-thecounter (OTC) options markets? Are illiquid options always priced lower than liquid options, similar to the liquidity effect consistently observed in the underlying asset markets, or does this depend on the institutional structure of the specific market, as suggested by Brenner et al. (2001)? We raise and answer this important question using cap and floor data from the OTC interest rate options market, which is one of the largest (and yet least researched) options markets in the world, with about $\$ 52$ trillion in notional principal and $\$ 700$ billion in gross market value outstanding as of June $2007 .^{6}$

Contrary to the accepted wisdom in the existing literature based on evidence from other asset markets, we find that more illiquid interest rate options in the OTC markets trade at higher prices relative to the more liquid options, controlling for other effects. This effect goes in the direction opposite to what is observed for stocks, bonds, and even for some exchange-traded currency options. Our paper is the first to document such a liquidity effect in any financial market, and is also the first one to examine liquidity effects in the OTC options markets. This result has important implications for incorporating liquidity effects in derivative pricing models, since we show that the conventional intuition, which holds in other asset markets, may not hold in some derivatives markets.

Our study contributes to the existing literature in several ways. According to the available evidence, the impact of illiquidity on asset prices is overwhelmingly presumed to be negative, since the marginal

\footnotetext{
${ }^{4}$ These include theoretical studies, such as Longstaff (1995a) and Longstaff (2001), numerous empirical studies in the equity markets, several studies such as Amihud and Mendelson (1991), Krishnamurthy (2002), Longstaff (2004), etc. in the Treasury bond markets, and Elton et al. (2001), Longstaff et al. (2005), De Jong and Driessen (2007), Nashikkar et al. (2009) and others in the corporate bond market. In addition, Amihud (2002) looks at the liquidity premium in a time-series context.

${ }^{5}$ In other related studies, Vijh (1990), George and Longstaff (1993), and Mayhew (2002) examine the determinants of equity option bid-ask spreads, while Bollen and Whaley (2004), Cetin et al. (2006), and Garleanu et al. (2008) examine the impact of supply and demand effects on equity option prices.

${ }^{6}$ BIS Quarterly Review, December 2007, Bank for International Settlements, Basel, Switzerland.
} 
investors typically hold a long position, thereby demanding compensation for the lack of immediacy they face if they wish to sell the asset. Thus, the liquidity premium on the asset is expected to be positive other things remaining the same, the more illiquid an asset, the higher is its liquidity premium and its required rate of return, and hence, the lower is its price. For example, in the case of a bond or a stock, which are assets in positive net supply, the marginal investor or the buyer of the asset demands compensation for illiquidity, while the seller is no longer concerned about the liquidity of the asset after the transaction. In fact, within a two-asset version of the standard Lucas economy, Longstaff (2008) shows that a liquid asset can be worth up to 25 percent more than an illiquid asset, when both have identical cash flow dynamics otherwise.

However, derivative assets are different from underlying assets like stocks and bonds. First, there is no reason to presume that liquidity in the derivatives markets is an exogenous phenomenon. Rather, it is the result of the availability and liquidity of the hedging instruments, the magnitude of unhedgeable risks, and the risk appetite and capital constraints of the marginal investors, among other factors. Thus, illiquidity in derivatives markets captures all of the concerns of the marginal investor about the expected hedging costs and the risks over the life of the derivative. In particular, in the case of options, since they cannot be hedged perfectly, the dealers are keen to carry as little inventory as possible, after allowing for hedging. Therefore, the liquidity of the option captures the ease with which a dealer can offset the trade. Consequently, the liquidity of an option matters to the dealers and has an effect on its price. Second, derivatives are generally in zero net supply. Therefore, in derivatives, it is not obvious whether the marginal investor concerned about liquidity holds a long or a short position. In addition, in the case of options, the risk exposures of the short side and the long side are not necessarily the same, since they may have other offsetting positions. Both the buyer and the seller continue to have exposure to the asset after the transaction, until it is unwound. The buyer demands a reduction in price to compensate for the illiquidity, while the seller requires an increase. Due to the asymmetry of the option payoffs, the seller has higher risk exposure than the buyer. The net effect of the illiquidity, which itself is endogenous, is determined in equilibrium, and one cannot presume ex ante that it will be either positive or negative, especially if the motivations of the two parties for engaging in the transaction (e.g. in their other positions) are different. 
These factors are especially prominent in the OTC interest rate cap and floor markets, which are institutional markets with hardly any retail presence. OTC markets are of special interest for the analysis of liquidity because of their different trading structure. In the absence of a centralized trading platform, such as a conventional exchange, prices have to be bilaterally negotiated between buyers and sellers. The buyers of caps and floors in an OTC market are typically (buy and hold investing) corporations attempting to hedge their interest rate risk. The sellers (derivative desks at large commercial and investment banks) in this market are concerned about hedging the risks of the caps and floors that they sell. While bid-ask quotations are normally posted by the dealers, there are search costs associated with finding them. The size of individual trades is relatively large, with the contracts being long-dated portfolios of options. The long-dated nature of the contract creates enormous transaction costs if the seller hedges dynamically using the underlying spot or derivative interest rate markets. Also, dealers cannot hedge the risks perfectly, due to maturity and basis differences, as well as contract size considerations. Moreover, the dealers have much shorter horizons relative to maturity of these caps and floors which can be as high as ten years. Thus, the dealers are interested in reversing their trades and holding as little inventory as possible. Hence, they are concerned about the liquidity of these options. ${ }^{7}$ Thus, for the purposes of pricing of liquidity, the marginal investor in this market is generally likely to be net short. Consequently, the market maker with a net short position may raise the price of illiquid options. ${ }^{8}$ Hence, illiquidity in this case has a positive relationship with the price, rather than the conventional negative relationship identified in the literature so far. This is indeed what we find, within an endogenous specification for option liquidity and prices. We provide cross-sectional evidence (in the limited sense possible for interest rate options) about the illiquidity premium by analyzing contracts at different strike rates. We also provide evidence on the time-series dimension of the illiquidity premium, as in Amihud (2002), by focusing only on ATM contracts over time.

Our result can be explained in the context of deviations from the Black-Scholes world. In the idealized setting of the hedging paradigm underlying that world, both the buyer and the seller can hedge

\footnotetext{
${ }^{7}$ In recent years, hedge funds have been quite active in this market. Based on our conversations with practitioners in this market, we understand that these players also typically have short positions in options.

${ }^{8}$ The results in Brenner et al. (2001), to the effect that illiquid currency options were priced lower than traded options, can also be explained by the same argument. In their case, illiquidity had a negative relationship with price. Since these options were auctioned by the Bank of Israel, the central bank, the buyers of these options were the ones who were concerned about illiquidity, and not the seller.
} 
continuously, perfectly and costlessly in the underlying market; consequently, illiquidity should not have an effect on the price of an option. However, in the real world, options cannot always be exactly and costlessly replicated, due to stochastic volatility, jumps, discrete rebalancing or transaction costs. ${ }^{9}$ There are also limits to arbitrage, as outlined in Shleifer and Vishny (1997) and Liu and Longstaff (2004). In addition, option dealers face model misspecification and biased parameter estimation risk (Figlewski (1989)). These factors result in some part of the risk in options becoming unhedgeable, leading to an upward sloping supply curve (Bollen and Whaley (2004), Jarrow and Protter (2005) and Garleanu et al. (2008)). In addition, since dealers in this market are net short, they may hit their capital constraints more often if they have to sell more options to make a market (Brunnermeier and Pedersen (2008)). They would, therefore, ask for more compensation for providing liquidity, thus making the supply curve upward-sloping.

Option liquidity is related to the slope of this upward-sloping option supply curve in three ways. First, the time when options become more illiquid may coincide with the time the sellers face greater unhedgeable risks, relative to their risk appetite and capital. In addition, it becomes more difficult for sellers to reverse their trades and earn the bid-ask spread. They face greater basis risk, since they have to hold an inventory of options that they cannot hedge perfectly. Second, the sellers face greater model risk when there is less liquidity - when there are fewer option trades, the dealers have less data to reliably calibrate their pricing models. Third, as modeled in Duffie et al. (2005), due to bilateral trading in OTC markets, dealers can have market power; hence, search frictions can increase bid-ask spreads as well as liquidity premia. ${ }^{10}$ All these factors result in an increase in the slope of the option supply curve when there is less liquidity, consistent with Cetin et al. (2006). The impact of a steeper supply curve on option prices and bid-ask spreads can be understood within the theoretical model of Garleanu et al. (2008). Given the inventory of the dealer, a steeper supply curve would result in wider bid-ask spreads, since the difference in prices for a unit positive, and negative, change in their inventory would be larger. In addition, if the net demand by

\footnotetext{
${ }^{9}$ Constantinides (1997) argues that, with transaction costs, the concept of the no-arbitrage price of a derivative is replaced by a range of prices, which is likely to be wider for customized, over-the-counter derivatives (which include most interest rate options), as opposed to plain-vanilla exchange-traded contracts, since the seller has to incur higher hedging costs to cover short positions, if they are customized contracts. In a similar vein, Longstaff (1995b) shows that in the presence of frictions, option pricing models may not satisfy the martingale restriction.

${ }^{10}$ The search costs may not change much on a daily basis. Thus, the contribution of the mechanism in Duffie et al (2005) to the time variation in the liquidity discount may be secondary.
} 
the end-users is positive (as in the case of interest rate caps and floors), a steeper supply curve will result in higher option prices, since the dealer is net short in the aggregate. ${ }^{11}$ In such a scenario, higher bid-ask spreads (lower liquidity) would be associated with higher prices, resulting in a liquidity discount, not a premium. Our empirical results are consistent with these implications, given the structure of the OTC interest rate options markets.

Although there is a plethora of research on liquidity effects in equity and debt markets, particularly in the United States, there is scant evidence in the case of derivative markets. Using data from the OTC interest rate options markets, our results underscore the fact that the positive relationship between liquidity and asset prices cannot be generalized to other markets without considering the structure of the market and the nature of the demand and supply forces. This fundamental point must be taken into account in both theoretical and empirical research. Since OTC interest rate derivatives form a substantial proportion of the global derivatives markets, our results could potentially provide insights into the broad question of liquidity effects in derivatives markets.

Recent work by Bongaerts et al (2009) presents a theoretical model of the pricing of liquidity and liquidity risk for derivatives. These authors show that the effect of liquidity on pricing can be a premium or a discount, depending on the relative wealth, risk aversion and horizon of buyers and sellers. They find empirically that for credit default swaps, it is the sellers who earn compensation for illiquidity.

The structure of our paper is as follows: In Section I we describe the data set and present summary statistics. After controlling for the term structure and volatility factors, a simultaneous equation system is employed to estimate and examine the relationship between the price (excess implied volatility relative to a benchmark) and the liquidity (relative bid-ask spread) of interest rate options. Section II presents the results for this relationship for various specifications. Section III concludes with a summary of the main results and directions for future research.

\footnotetext{
${ }^{11}$ Garleanu et al (2008) do not specifically examine the relationship between illiquidity and the prices of derivative assets. Their main focus is on the effects of the changes in inventory on prices through movement along the supply curve. However, their set-up is also useful in understanding the changes in the slope of the supply curve and the resultant relationship between illiquidity and option prices.
} 


\section{Data}

The data for this study consist of an extensive collection of euro $(€)$ interest rate cap and floor prices over the 29-month period from January 1999 to May 2001, obtained from WestLB (Westdeutsche Landesbank Girozentrale) Global Derivatives and Fixed Income Group. These are daily bid and offer price quotes over 591 trading days for nine maturities (two years to ten years, in annual increments) across twelve different strike rates ranging from $2 \%$ to $8 \%$. On a typical day, price quotes are available for about $30-40$ caps and floors, reflecting the maturity-strike combinations that exhibit market interest on that day. We present below some descriptive statistics of our data. We then explain why our data are representative of the market quotes even though our prices come from a single dealer.

\section{A. Descriptive Statistics}

Our data set allows us to conduct our empirical analysis for caps and floors across strike rates. These caps and floors are portfolios of European interest rate options on the six-month Euribor with a six-monthly reset frequency. In Appendix A, we provide details of the contract structure for these options. Along with the options data, we also collected data on euro swap rates, and the daily term structure of euro interest rates, from the same source. These are key inputs necessary for conducting our empirical tests.

Table I provides descriptive statistics on the midpoint of the bid and ask prices for caps and floors over our sample period. The prices of these options can be almost three orders of magnitude apart, depending on the strike rate and the maturity of the option. For example, a deep out-of-the-money, two-year cap may have a market price of just a few basis points, while a deep in-the-money, ten-year cap may be priced above 1500 basis points. Since interest rates varied substantially during our sample period, the data have to be reclassified in terms of "moneyness" ("depth in-the-money") to be meaningfully compared over time. In table I, the prices of options are grouped together into "moneyness buckets," by calculating the Log Moneyness Ratio (LMR) for each cap/floor. The LMR is defined as the logarithm of the ratio of the par swap rate to the strike rate of the option. Therefore, a zero value for the LMR implies that the option is at-the-money forward, since the strike rate is equal to the par swap rate. Since the relevant swap rate changes every day, the moneyness of the same strike rate, same maturity, option, as measured by the LMR, also changes each day. The average price, as well as the standard deviation of these prices, in basis 
points, are reported in the table. It is clear from the table that cap/floor prices display a fair amount of variability over time. Since these prices are grouped together by moneyness, a large part of this variability in prices over time can be attributed to changes in volatilities over time, since term structure effects are largely taken into account by our adjustment.

We also document the magnitude and behavior of the liquidity costs in these markets over time, for caps and floors across strike rates. We use the bid-ask spreads for the caps and floors as a proxy for the illiquidity of the options in the market. In an OTC market, this is the only measure of illiquidity available for these options. Other measures of liquidity common in exchange-traded markets such as volume, depth, market impact etc., are just not available. In our sample, we do observe the bid-ask spread for each option every day. Therefore, we settle for using this metric as a meaningful, although potentially imperfect, proxy for liquidity. ${ }^{12}$

It is important to note that these bid-ask spreads are measures of the liquidity costs in the interest rate options market and not in the underlying market for swaps. Although the liquidity costs in the two markets may be related, the bid-ask spreads for caps and floors directly capture the effect of various frictions in the interest rate options market, along with the transaction costs in the underlying market, as well as the imperfections in hedging between the option market and the underlying swap market. Therefore, the bid-ask spread of the option is the liquidity proxy relevant for pricing analysis.

In table II, we present the relative bid-ask spreads (RelBAS), defined as the bid-ask spreads divided by the mid price (the average of the bid and ask prices) of the option, grouped together into moneyness buckets by the LMR. It is important to note that, in general, these bid-ask spreads are much larger than those for most exchange-traded options. Close-to-the-money caps and floors have relative bid-ask spreads of about $8-9 \%$, except for some of the shorter-term caps and floors that have higher bid-ask spreads. Since deep in-the-money options (low strike rate caps and high strike rate floors) have higher prices, they have lower relative bid-ask spreads (3-4\%). Some of the deep out-of-the-money options have large relative bid-

\footnotetext{
${ }^{12}$ The bid-ask spread is a widely accepted proxy for liquidity used by numerous prior studies, including Amihud and Mendelson (1986), and has been shown to be highly correlated with other proxies for liquidity. In addition, in the spot fixed income markets, Fleming (2003) and Goldreich, Hanke and Nath (2005) show that the bid-ask spread quoted by market makers who supply liquidity better measures the value investors place on immediacy, rather than the actual trade prices, trade sizes, or trading volume. They also show that the bid-ask spreads are highly correlated with price impact coefficients, similar to the ILLIQ measure of Amihud (2002).
} 
ask spreads - for example, the two-year deep out-of-the-money caps, with an average price of just a couple of basis points, have bid-ask spreads almost as large as the price itself, on average about $80.9 \%$ of the price. Part of the reason for this behavior of bid-ask spreads is that some of the costs of the market makers (transaction costs on hedges, administrative costs of trading, etc.) are fixed costs that must be incurred whatever may be the value of the option sold. However, some of the other costs of the market maker (inventory holding costs, hedging costs, etc.) are dependent on the value of the option bought or sold. Having presented some preliminary statistics, we now argue that our data are representative of the market as a whole, even though they were obtained from a single dealer.

\section{B. Representativeness of the Data}

There is no single source of market-wide data for most over-the-counter markets. ${ }^{13}$ This presents a major challenge to researchers since there is a choice between collecting data from one or a handful of dealers and not being able to study the market at all. Unfortunately, this is an issue in the interest rate options market that we study here. Our data provider, WestLB, is one of the dealers who subscribe to the interest rate option valuation service from Totem. Totem is the leading industry source for asset valuation data and services supporting independent price verification and risk management in the global financial markets. Most derivative dealers subscribe to their service. As part of this service, Totem collects data for the entire "skew" of caplets and floorlets across a series of maturities from its set of dealers. They aggregate this information and return the consensus values back to the dealers that contribute data to them. The market consensus values supplied to the dealers include the underlying term structure data, caplet and floorlet prices, as well as the prices and implied volatilities of the reconstituted caps and floors across strike rates and maturities. Hence, the prices quoted by dealers such as WestLB that are a part of this service reflect market-wide consensus information about these products. This is especially true for plain-vanilla caps and floors, which are very high-volume products with standardized structures that are also used by dealers to calibrate their models for pricing and hedging exotic derivatives. Our discussions with market participants confirm that there is virtually no systematic variation in quotes across the dealers

\footnotetext{
${ }^{13}$ Important recent exceptions to this statement are the U.S. corporate bond market after the advent of the Trade Reporting and Compliance Engine (TRACE) data base under the auspices of the Financial Industry Regulatory Authority (FINRA), and the syndicated loan secondary market where the Loan Syndications and Trading Association (LSTA) collects and distributes secondary loan prices to subscribing market participants (see Gupta et. al. (2008) for more information on the secondary loan market).
} 
who subscribe to Totem, especially for plain-vanilla products like the interest rate caps and floors that we study in this paper. These are relatively standardized options that are traded in large volumes every day, where dealers are active on the bid and the ask sides on a daily basis. According to our sources, for such vanilla products, a large dealer, especially one who subscribes to Totem, cannot afford to be systematically away from the "market" (quotes from other dealers) on either the bid or the ask side, since they would either lose business right away, or be hit with a deluge of orders. Furthermore, since these are plain vanilla products, the price quotes to institutional clients do not deviate systematically from those in the inter-dealer market, due to the high level of activity in the market in both segments.

In addition, since WestLB had to mark its trading books to market every day, it would be highly unlikely that they would use one set of prices as quotes to their customers, but use a different set of prices for marking-to-market, since this would violate prudent risk management controls. Using different prices for the front office and for the profit and loss account would ultimately cause huge issues of reconciliation and also client satisfaction. Thus our data are representative of the market prices for these caps and floors. $^{14}$

Another way to assess the representativeness of our data is to consider the competitiveness of the market. The euro OTC interest rate derivatives market is extremely competitive, especially for plain-vanilla contracts like caps and floors. The BIS estimates the Herfindahl index (sum of squares of market shares of all participants) for euro interest rate options (which includes exotic options) at about 500-600 during the period from 1999 to 2004, which is even lower than that for USD interest rate options (around 1,000), compared to a range of $0-10,000$ (where 0 indicates a perfectly competitive market and 10,000 a market dominated by a single monopolist.) The Herfindahl index values indicates that the OTC interest rate options market is a fairly competitive market; hence, it is safe to rely on option quotes from a top European derivatives dealer (reflecting the best market consensus information available with them) such as WestLB during our sample period. Given the competitive structure of the market, any dealer-specific effects on the quotes are likely to be small and unsystematic.

\footnotetext{
${ }^{14}$ The use of market dealer quotations for studying liquidity effects is consistent with several prior studies, including Longstaff et al. (2005).
} 
We also compare our mid-prices to the mid-prices for ATM interest rate caps and floors, provided by DataStream for this period. We cannot use the data provided by DataStream for our study because they do not provide bid and ask quotes, and also do not have even mid-prices for options that are away-from-themoney. However, we find an almost perfect correlation between their ATM mid-price implied volatilities and our near-the-money mid-price implied volatilities. These near-perfect correlations rule out the possibility that the dealer's quotes are skewed to one side due to inventory concerns. Inventory concerns would mean that both the bid and ask quotes are too low or too high compared to the market quotes thus making the dealer's mid-quotes deviate from the market mid-quotes.

We also examine the representatitiveness of our bid-ask spreads by comparing them to the estimated bidask spreads for options on 3-month Euribor futures that are traded on the LIFFE. As mentioned on LIFFE's website, these options are part of LIFFE's Euribor contract suite, which is extremely liquid and accounts for $99 \%$ of money market activity for exchange-traded derivatives on the Euro-denominated short term interest rate. Ideally, we would have liked to compare our bid-ask spreads with bid-ask spreads for Euribor caps and floors from a different source. Unfortunately, such data do not exist for the Euribor options. However, the next best alternative is to compare the magnitude of our bid-ask spreads with those of interest options on the same underlying yield curve.

LIFFE data on these options do not provide bid and ask quotes directly. However, they do have daily high, low and closing prices. We use the procedure suggested in Corwin and Schultz (2008) to estimate the bid-ask spreads from daily high and low prices. We modify this procedure so that it can be applied to options and find that the average bid-ask spread is 3.6\% for these options. Using the model in Roll (1984), we get average bid-ask spreads of $11 \%$. For the same moneyness as these options, the bid-ask spreads for caps and floors in our sample average to $8.7 \%$. Caps and floors are OTC derivatives, and are likely to have higher bid-ask spreads than those for the more liquid exchange-traded options on Euribor futures. Thus, the average bid-ask spreads in our sample do not appear to be too wide. We provide the details of the estimation of the bid-ask spreads for the LIFFE options in Appendix B.

Having established the reasonableness of our mid-quotes as well bid-ask spreads, we now turn to answering the question about the pricing of liquidity. 


\section{The Pricing of Liquidity in OTC Interest Rate Options}

We use the flat implied volatilities from the Black-BGM model, estimated using mid-prices (the average of bid and ask) to characterize option prices throughout the analysis from here on. ${ }^{15}$ Since our primary objective is to examine liquidity effects in interest rate option markets, we focus on the traded assets, which are caps and floors. Therefore, we use the flat volatilities of caps and floors, since the spot volatilities would correspond to caplets and floorlets, which are untraded assets. The raw implied volatility obtained from the Black BGM model removes underlying term structure effects from option prices. ${ }^{16}$ Therefore, a change in the implied volatility of an option from one day to the next can be attributed to changes in interest rate uncertainty, or other effects not captured by the model, and not simply due to changes in the underlying term structure. We then estimate the excess implied volatility (EIV, similar to that used in Garleanu et al. (2008)) as the difference between the implied volatility and a benchmark volatility estimated using a panel GARCH model on historical interest rates. We check for the robustness of our results by estimating the benchmark volatility using several alternative methods. The EIV is a cleaner measure of the expensiveness of options, since even the general level of interest rate volatility has been factored out of the implied volatility of each option contract. In addition, in the empirical tests where we use EIV, we control for the shape of the volatility smile (using functions of LMR), and use several term structure variables as well as approximate controls for the skewness and excess kurtosis in the underlying interest rate distribution. In the presence of these controls, the changes in the EIV for a particular option cannot be attributed to changes in the underlying term structure or to changes in the general level of interest rate volatility. Therefore, the EIV can be effectively used to examine factors, such as liquidity, other than the underlying term structure or interest rate uncertainty that

\footnotetext{
${ }^{15}$ The use of implied volatilities, from a variant of the Black-Scholes model, even though model- dependent, is in line with all prior studies in the literature, including Bollen and Whaley (2004). The details of the calculation of implied volatility are provided in the Appendix.

${ }^{16}$ Our implied volatility estimation is likely to have much smaller errors than those generally encountered in equity options (see, for example, Canina and Figlewski (1993)). We pool the data for caps and floors, which reduces errors due to misestimation of the underlying yield curve. The options we consider are more long term (the shortest cap/floor has a two-year maturity), which reduces this potential error further. For most of our empirical tests, we do not include deep ITM or deep OTM options, where estimation errors are likely to be larger. Furthermore, since we consider the implied flat volatilities of caps and floors, rather than spot volatilities, the errors are even further reduced due to the implicit "averaging" in this computation. The "flat" volatility is the weighted average of the volatilities for all the caplets/floorlets in a cap/floor, while the "spot" volatility is the volatility of an individual caplet/floorlet.
} 
may affect option prices in this market. ${ }^{17}$ In the rest of the paper, we use the EIV as a measure of the expensiveness of the option, for every strike and maturity.

\section{A. Panel GARCH Model for Benchmark Volatility}

The GARCH models proposed by Engle (1982) and Bollerslev (1986) have been extended to explain the dynamics of the short-term interest rate by Longstaff and Schwartz (1992), Brenner et al. (1996), Cvsa and Ritchken (2001), and others. These studies find that for modeling interest rate volatility, it is important to allow the volatility to depend both on the level of interest rates and on unexpected information shocks. The asymmetric volatility effect as modeled in Glosten, Jagannathan, and Runkle (GJR, 1993) has also been found to improve volatility forecasts. In particular, these studies recommend using a GJR-GARCH $(1,1)$ model with a square-root type level dependence in the volatility process.

However, for estimating the relevant benchmark volatilities for caps/floors, we need to model forward rate volatilities. These present an additional challenge, since the volatilities for different forward rate maturities, while being different, are linked together due to the common factors that drive the entire term structure of interest rates. Therefore, the entire term structure of forward rate volatilities must be estimated simultaneously in an internally consistent modeling framework. We extend this literature and develop a panel GARCH model with the following process for forward rates:

$$
\begin{aligned}
& f_{t, T}=\alpha_{0}+\alpha_{1} f_{t-1, T}+\varepsilon_{t, T}, \quad \varepsilon_{t, T} \sim N\left(0, h_{t, T}^{2}\right) \\
& h_{t, T}=\sigma_{t, T} \sqrt{f_{t-1, T}} \\
& \sigma_{t, T}^{2}=\beta_{0}+\beta_{1} \sigma_{t-1, T}^{2}+\beta_{2} \varepsilon_{t-1, T}^{2}+\beta_{3} \varepsilon_{t-1, T}^{2} I_{t-1, T}^{-}, \quad I_{t-1, T}^{-}=1 \text { if } \varepsilon_{t-1, T}<0
\end{aligned}
$$

where $f_{\mathrm{t}, \mathrm{T}}$ is the six-month tenor forward rate, T periods forward, observed at time t. This is a panel version of the GJR-GARCH(1,1) model with square-root level dependence. It is a parsimonious, yet very flexible, model that nests many widely used GARCH models, as well as the continuous time term structure models in the Heath, Jarrow, and Morton (HJM, 1992) framework, including the Cox, Ingersoll, and Ross (CIR, 1985) model. We estimate this panel GARCH model using the maximum likelihood

\footnotetext{
${ }^{17}$ Changes in the EIV, in the presence of these controls, are somewhat analogous to the excess returns used in asset pricing studies.
} 
method and the Marquardt-Levenberg algorithm. We have a panel of 19 forward rates of six-month tenor with maturities ranging from six-months to 9.5 years in increments of six months each. For each day, we estimate the GARCH model on the history of the forward rates available up to that day. We impose a minimum requirement of 66 days of data (about three months) which gives us sufficient observations (66 $\mathrm{x} 19=1,254)$ to estimate this panel GARCH model reliably. Based on the estimated model, we forecast the one-day-ahead volatilities of all the forward rates, and use this forecast as a proxy for the expected volatility of the relevant maturity forward rate. Using these forward rate volatility forecasts, we price each caplet individually using the Black model, and then invert the resultant at-the-money cap price to obtain the flat implied volatility which is then used as the benchmark volatility in the EIV calculation. We use the panel GARCH model as a sophisticated way of extracting information from historical volatility, which we convert into a consistent benchmark through the Black model. ${ }^{18}$

In addition to using this panel GARCH model to estimate the benchmark volatility, we employ two alternative volatility measures as benchmarks to compute the EIV for additional robustness. The first is a simple historical volatility estimated as the annualized standard deviation of changes in the log forward rates of different maturities, using the past 66 days of forward rate data (our results are again robust to different choices of this historical time window). The second alternative volatility measure we use is a comparable implied volatility from the swaption market. We use only the at-the-money "diagonal" swaption volatilities since they are the most actively traded swaption contracts in the market. For example, for the two-year caps/floors, we use the 1x1 swaption (one-year option on the one-year forward swap) volatility as the relevant benchmark, since the $1 \mathrm{x} 1$ swaption price reflects the volatilities of forward rates out to two-years in the term structure. Similarly, for the four-year caps/floors, we use the $2 \times 2$ swaption volatility as the benchmark volatility. For the three-year caps/floors, we use the average of the $1 \times 1$ and the $2 \times 2$ swaption volatilities. The other benchmark volatilities are calculated in a similar manner.

It is important to note that the first two benchmark volatility measures (the panel GARCH based volatility and simple standard deviation) are both historical volatility measures. In principle, one could forecast the

\footnotetext{
${ }^{18}$ We do extensive robustness tests using several alternative specifications of the panel GARCH model (including a specification with a parametric volatility hump similar to the one in Fan et al. (2007)), to ensure that our results are not driven by any particular choice of a model for the benchmark volatility. These results are not presented in the paper to save space, but can be furnished by the authors, upon request.
} 
volatility of forward rates over the life of the cap/floor using the panel GARCH model. However, given the long maturity of interest rate options like caps/floors (unlike most equity options) such forecasts are likely to be unreliable. As a result, we use these two alternative historical volatility measures (panel GARCH and standard deviation) as proxies for the expected volatility. It is important to note that these measures capture the historical volatility of the forward rates of appropriate maturity; hence, the long duration of the particular caps and floors is automatically taken into account to some extent. The advantage of the panel GARCH methodology is that it extends to forward rates a model that has been shown to work well for forecasting the short rate volatility. The advantage of the historical standard deviation is its simplicity and freedom from the imposition of any particular model structure. However, both these benchmarks suffer from the fact that they are backward looking, whereas option prices are based on forward looking volatilities. The volatility from the swaption market provides us with a measure of the expected volatility in the underlying Euribor market (which is common to both caps/floors as well as swaptions) over the maturity of the cap/floor, but from a different market that is not directly influenced by the liquidity effects in the cap/floor markets. These three benchmark volatility measures, applied separately, complement each other and inspire confidence in the robustness of our results.

Figure 1 presents the scatter plots for the EIV across moneyness represented by LMR for our three benchmark volatility measures - panel GARCH, standard deviation, and swaption implied volatility. The plots are presented for three representative maturities - two-year, five-year, and ten-year - for the pooled cap and floor data. The plots for the other maturities are similar. These plots clearly show that there is a significant smile curve, across strike rates, in these interest rate options markets. The smile curve is steeper for short-term options, while for long-term options, it is flatter and not symmetric around the at-the-money strike rate. It is also important to note that the range of moneyness observed in this market is much greater than that generally observed in the equity markets. For example, for two-year caps/floor, it is not uncommon to find options that have strike rates that are $40 \%-50 \%$ higher or lower than the at-the-money strike rate. We classify the options that have LMRs between -0.1 and 0.1 as being at-the-money, since the volatility smile is virtually non-existent within this moneyness range. 


\section{B. $\quad$ The Relationship between Liquidity and Option Prices}

As argued in the literature, the relationship between the liquidity of an asset and its price is of fundamental importance in any asset market. For common underlying assets like stocks and bonds usually more liquid assets will have lower returns and higher prices. However, for derivative assets, especially those in zero net supply where it is not clear whether the marginal investor would be long or short, this relationship may go either way. In this subsection, we examine this relationship for OTC euro interest rate caps and floors.

To gain an initial understanding of this relationship, we first estimate the correlation between the EIV and the RelBAS for all maturities for all three of the benchmark volatility measures. For example, the correlation between the EIV (based on the panel GARCH model) and the RelBAS is about 0.41 for twoyear maturity caps/floors, 0.35 for five-year maturity caps/floors, and 0.44 for ten-year maturity caps/floors, which are all statistically significantly greater than zero. ${ }^{19}$ Figure 2 presents the sample scatter plots for the two, five, and ten-year maturity options, for all three benchmark volatility measures. The plots for the other maturities are similar. Across all the nine maturities, we find that the average of the correlation coefficients (between the EIV and the RelBAS) is 0.41 using the panel GARCH based benchmark volatility, 0.44 using the historical standard deviation based benchmark volatility, and 0.43 using the swaption based benchmark volatility. Although these are just "raw" correlations between option expensiveness and illiquidity, they do indicate that, on average, more illiquid options appear to be more expensive across all moneyness buckets and maturities.

Illiquidity, especially for a derivative asset, arises endogenously due to the fundamental frictions in financial markets. In particular, the bid-ask spreads capture the slope of the supply curve of the dealers, which is affected by hedging costs, the extent of unhedgeable risks, and the dealers' risk appetite and capital. Liquidity in a broader sense also captures the ease with which the market-makers can find an offsetting trade. Even though dealers may find offsetting trades for part of their inventory, they would still prefer to carry as little inventory as possible. Therefore, finding an offsetting trade, and hence the liquidity of the options themselves, matters to them. To the extent that they cannot find an offsetting

\footnotetext{
${ }^{19}$ The correlations between the EIV and the RelBAS are positive and significant using either bid or ask prices, as well.
} 
trade, they would charge a premium to carry that inventory. In this manner, liquidity could be both a "cause" and an "effect". In fact, in the context of a dynamic trading model, Gallmeyer et al. (2007) show that, especially for long-dated securities, the demand discovery process leads to endogenous joint dynamics in prices and liquidity. Thus, both liquidity and price can have an effect on each other, and it is likely that they are jointly determined by a set of exogenous macro-financial variables. Therefore, we model this endogenous relationship within a simultaneous equation model of liquidity (relative bid-ask spreads) and price (EIV), using macro-financial variables as the exogenous determinants of these two endogenous variables.

\section{B.1. $\quad$ Liquidity Effects in ATM Options}

Unlike underlying asset markets, options markets have another dimension (the strike price/rate) along which both liquidity and prices change, as shown in the figures above. There is a smile (or a skew) across strike rates in both implied volatilities as well as liquidity. These smiles/skews arise in part due to the skewness and excess kurtosis in the distribution of the underlying interest rates. In order to clearly disentangle liquidity effects from any effects arising due to the volatility smiles/skews observed in this market, we first focus only on at-the-money options, with LMRs between -0.1 and 0.1 . More precisely, these options are near-the-money, instead of being truly at-the-money. However, as shown in figure 1, the volatility smile is virtually flat within this moneyness range; hence, the smile effects, if any, are negligible for these options. ${ }^{20}$ In spite of the smile being virtually flat for these at-the-money options, we control for any residual smile effects within this moneyness bucket using an asymmetric quadratic function of LMR that best explains the variation in EIV as well as in RelBAS across strikes. ${ }^{21}$ Therefore, we use LMR, $L M R^{2}$, and $\left(1_{L M R<0 .} L M R\right)$ as controls for any residual strike rate effects for both liquidity and price in the simultaneous equation model.

Our discussions with market participants revealed that the dealers consider the vega and the moneyness of the options as proxies for the inventory risk they face, while setting bid-ask spreads. As a good

\footnotetext{
${ }^{20}$ In additional tests, we find that our results are robust to narrower (LMRs between -0.05 and 0.05) or wider (LMRs between -0.15 and 0.15 ) LMR ranges for defining options as being at-the-money.

${ }^{21}$ This is based on our examination of alternative functional forms using pooled time-series cross-sectional regressions of EIV and RelBAS on various functions of LMR, and is consistent with the appearance of the plots presented in Figure 1. Our results are robust to the exclusion of these LMR controls for the at-the-money options.
} 
approximation, vega can be expressed as a quadratic function of the moneyness of the option. Thus, the inclusion of these LMR controls in the RelBAS equation also takes care of the dependence of bid-ask spreads on vega and on moneyness. The objective of such LMR controls in both the equations is to filter out any residual dependence of EIV and RelBAS on the moneyness of the option, and examine whether there is still any relationship between these two variables, as well as between these two variables and the exogenous variables in the model.

Therefore, we estimate the following equation system for ATM options with LMRs between -0.1 and 0.1:

$$
\begin{gathered}
\text { EIV }=c 1+c 2 * \text { RelBAS }+c 3 * L M R+c 4 * L M R^{2}+c 5 *\left(1_{L M R<0} . L M R\right)+ \\
c 6 \text { SwpnVol }+c 7 * \text { DefSprd }+c 8 * 6 M r a t e+c 9 * \text { Slope } \\
\text { RelBAS }=d 1+d 2 * \text { EIV }+d 3 * L M R+d 4 * L M R^{2}+d 5 *\left(1_{L M R<0} . L M R\right)+ \\
d 6 * \text { SwpnVol }+d 7 * \text { DefSprd }+d 8 * \text { LiffeVol }+d 9 * \text { CpTbSprd }
\end{gathered}
$$

The two-equation simultaneous-equations model above has two endogenous variables (EIV and RelBAS), a vector of LMR controls, and a vector of exogenous variables in both the equations for model identification. The intuition behind the choice of the exogenous variables is explained below. In econometric tests reported later in the paper, we examine the validity and strength of these variables as instruments.

Although we have already benchmarked the cap/floor implied volatility against various proxies for the expected interest rate volatility, we include the swaption volatility (SwpnVol) in the first equation to account for any residual dependence of the EIV on the level of volatility. We also include the swaption volatility as an explanatory variable for relative bid-ask spreads since greater uncertainty would make a risk-averse market maker demand higher compensation for providing liquidity and hence result in higher bid-ask spreads. The ATM swaption volatility, which is from a different but related market, can be interpreted as a general measure of the future interest rate volatility.

Caps and floors are over-the-counter options not backed by a clearing corporation or an exchange. Hence the level of credit risk may affect the pricing as well as the liquidity of these options. To account for this 
effect, we include the six-month German Treasury-Euribor Spread (DefSprd) as a measure of the aggregate default risk of the constituent banks in the Euribor fixing.

In the first equation of the simultaneous equation model, we include the spot six-month Euribor (6Mrate) and the slope of the yield curve (Slope, defined as the difference between the five-year and six-month spot rates) as instruments for EIV. These variables are used as proxies of the expectations of the market about the direction in which interest rates are expected to move in the future. They also reflect the expectations in the financial markets about future inflation and money supply, which are fundamental determinants of the term structure of interest rates and its volatility. Thus, these yield curve variables are likely to capture the demand for these interest rate options and hence affect EIV of these options. However, it is unlikely that the yield curve variables have a direct effect on the relative bid-ask spreads of these options. Therefore, we use them as instruments for the excess implied volatilities.

Typically, in models of interest rates displaying skewness and excess kurtosis, the future distribution of interest rates depends on the current day's volatility and on the level of interest rates. Thus, by including the contemporaneous volatility and interest rate variables in the EIV regression, we try to approximately control for non-normal distribution of future interest rates, without explicitly considering a more detailed structural model for interest rates. ${ }^{22}$

In the second equation of the simultaneous equations model, we include the logarithm of the trading volume of the three-month Euribor futures contract on the London International Financial Futures Exchange i.e. LIFFE ( $\mathrm{LiffeVol}$ ) and the spread between the three-month AA financial CP rate and the three-month Treasury bill rate $(C p T b S p r d)$ as instruments for the relative bid-ask spreads. The Euribor futures volume is a proxy for trading activity due to interest rate hedging demand. There are no volume data available for caps and floors, since they are traded over-the-counter. However, the Euribor futures volume is likely to be positively correlated with the trading volume (and liquidity) for caps and floors, since, to some extent, they are substitute products for hedging interest rate risk. However, there is no reason for the Euribor futures volume to affect the excess implied volatilities of these options, except through liquidity effects. Therefore, it is likely to be a valid instrument for the relative bid-asks spreads.

\footnotetext{
${ }^{22}$ Our results for the ATM bucket are robust to the explicit inclusion of the historical skewness and excess kurtosis of the interest rate distribution as additional controls in the simultaneous equation model.
} 
Since the CP market is illiquid in comparison with the T-bill market, the spread in the rates of the commercial paper (CP) over the Treasury bill (T-bill) rates can be used as a proxy of the aggregate liquidity demand. ${ }^{23}$, Therefore, this spread is likely to be positively correlated to the bid-ask spreads of caps and floors to the extent that macro institution-level liquidity may be correlated with micro contractlevel liquidity. However, it is unlikely that this spread would affect the excess implied volatilities of these options, except through their effect on liquidity. Hence, it is a valid instrument for the relative bid-ask spreads.

These macro-financial variables, taken together, incorporate most of the relevant information about fundamental economic indicators, such as the expected inflation, the GDP growth rate, and risk premia. The macro-financial variables along with the LIFFE futures volume also control for the volatility risk premium in this market. Since the fundamental economic variables are available at most monthly, we must rely on daily proxies for the expectations of these economic factors in the financial markets. ${ }^{24}$

This simultaneous equation model is estimated using three-stage least squares, since the residuals in each equation may be correlated with the endogenous variables, and these residuals may also be correlated across the two equations. We use instrumental variables to produce consistent estimates, and generalized least squares (GLS) to account for the correlation structure of the residuals across the two equations. In the first stage, we develop instrumented values for both the endogenous variables, using all exogenous variables in the system as instruments. In the second stage, based on a two-stage least squares estimation of each equation, we obtain a consistent estimate of the covariance matrix of the equation disturbances. Using this covariance matrix of residuals from the second stage, and the instrumented values of the endogenous variables from the first stage, we then perform a GLS estimation as the third stage of the three-stage least squares estimation.

The results for this model are presented in table III. To save space, we do not present the coefficients for the LMR controls. They are mostly insignificant, consistent with the fact that the implied volatility smile is almost flat in the near-the-money region that we consider. Our primary inference is regarding the sign

\footnotetext{
${ }^{23}$ This use is consistent with several prior studies, including Krishnamurthy (2002) and Gatev and Strahan (2006).

${ }^{24} \mathrm{We}$ considered other macro-financial variables as well, such as yields on speculative grade long-term debt, the short term repurchase (repo) rate as a proxy for money supply, and the volatility and stock returns in European equity markets. These variables were eliminated due to collinearity with the variables included in the model.
} 
of the coefficients $\mathrm{c} 2$ and $\mathrm{d} 2$. Both these coefficients are positive and statistically significant for all option maturities. This shows that for ATM options, within the endogenous framework specified above, controlling for potential exogenous drivers of price and liquidity in this market, higher values of EIV are associated with higher values of RelBAS, and vice-versa. In other words, more liquid options are priced lower, while less liquid options are priced higher, after taking into account the effects of the macro and control variables. This is an important result, and is quite different from the relationship between price and liquidity observed in other asset markets, such as those for stocks and bonds. For example, in the equity markets, it has been shown that more liquid stocks have lower returns (higher prices); what we observe here is the opposite; that is, that more liquid options have lower prices. Thus in this market, higher liquidity is actually associated with a discount, not a premium.

The primary explanation for this result is the fundamental difference between derivative assets and underlying assets alluded to in the introduction. Derivatives are in zero net supply; therefore, it is unclear whether the marginal investor concerned about illiquidity in these assets would be long or short. In addition, the long and short positions in derivatives have asymmetric risk exposures (especially for options), and present different hedging needs to the counterparties on both sides. As argued by Brenneret al. (2001), for an asset in zero net supply, both the buyer and the seller are concerned about illiquidity pushing the prices in the opposite directions. Depending on the risk exposure and the hedging needs of each side, either the "buyer-effect" (lower prices for illiquid assets) or the "seller-effect" (higher prices for illiquid assets) could dominate.

In the OTC market for interest rate options, we find that the "seller-effect" dominates and the more illiquid options have higher prices. From our discussions with the market participants it is clear that, in general, in this market, the dealers are net sellers of these options whereas the corporate entities are the net buyers. On any given day, a substantial proportion of the trades in the OTC interest rate options market are sell-side trades where banks sell caps and floor to corporate clients. ${ }^{25}$ The corporate end-users buy these options to hedge their other interest rate exposures and are usually not concerned about the liquidity of the options, since they typically hold these options to maturity. On the other hand, the dealers,

\footnotetext{
${ }^{25}$ An experienced market maker, who was the global head of the interest rate options desk at one of the largest banks in the world put the proportion of sell-side trades at between $80 \%$ and $90 \%$ on any given day. Unfortunately, there are no hard data available to substantiate his estimate.
} 
who are net sellers, are concerned about the liquidity of the options because it captures the effects of imperfect hedging, limited risk appetite and capital constraints (Figlewski (1989) and Garleanu et al. (2008)). ${ }^{26}$ Limited risk appetite and capital constraints may be a result of the agency considerations between the dealers and their financiers. Imperfect hedging may be due to the trading frictions in the underlying asset markets, as well as the presence of risks in options that cannot be hedged using the underlying assets (such as unspanned stochastic volatility or jumps). There is basis risk between options of different strikes and maturities, which makes it impossible to exactly offset a short position in an illiquid option by buying a liquid option at a different strike and/or maturity. In such a scenario, when option market-makers sell illiquid options, it is difficult for them to find an offsetting trade and earn the bid-ask spread on the option right away (which is something traders generally try to do). Furthermore, the dealers are exposed to greater model risk, when there is less liquidity in the market, since they have fewer traded prices available to reliably calibrate their pricing models. Therefore, they are exposed to unhedgeable risks for which they demand compensation by way of higher option prices on more illiquid contracts. The resulting increase in the slope of the upward sloping option supply curve (Bollen and Whaley (2004) and Garleanu et al. (2008)) increases the bid-ask spreads as well as the option prices, consistent with our findings. Thus, given the structure of this particular market, it is not surprising that the "seller-effect" dominates and that the illiquid options trade at higher prices.

We can examine the magnitude of the coefficient $\mathrm{c} 2$ to determine the economic significance of the responsive of EIV to relative bid-ask spreads. Depending upon maturity, the excess implied volatilities increase by 25 to 70 basis points for every percentage point increase in the relative bid-ask spreads of these options. Alternatively, we can estimate the absolute price impact of a one standard deviation change in the relative bid-ask spread of an option. For example, the standard deviation of the relative bid-ask spreads of five-year caps and floors is about $2.3 \%$. Therefore, a one standard deviation shock to the liquidity of the ATM five-year caps and floors would translate into a 115 basis point increase in their

\footnotetext{
${ }^{26}$ Garleanu et al (2008) focus on the effects of changing inventory on the prices of derivatives due to the risk aversion of the dealer and imperfect hedging. However, their set-up is also useful for examining the relationship between the prices and bid-ask spreads given the level of inventory. Changing levels of inventory affect the prices through movement along a given supply curve, whereas the relationship between the bid-ask spreads and prices is a result of the changing slope of the supply curve. Our empirical analysis examines the latter relationship rather than the former. Our analysis is not meant to throw any light on the extent to which the changes in the levels of inventory affect prices, but not bid-ask spreads. However, we control for macro-economic variables that capture the changes in the demand for these options, and hence the changing levels of dealers' inventory.
} 
excess implied volatility, given a c2 coefficient of 0.50 . For representative interest rates and ATM volatility, this is equivalent to an increase of about $5 \%$ in the absolute price (the price in Euros) of the five-year ATM cap/floor. In general, for other maturities, a one standard deviation shock to the liquidity of a cap/floor translates into an absolute price change of between $4 \%$ and $8 \%$, which is an economically significant magnitude.

In addition, we see that the coefficients $\mathrm{c} 2$ and $\mathrm{d} 2$ are generally increasing in the maturity of these options. This indicates that the longer maturity options exhibit a stronger liquidity effect, perhaps to compensate the seller for the illiquidity over a longer time frame. This is consistent with the effect reported by Goldreich et al. (2005) in the U.S. Treasury securities market, where the average liquidity over the asset's remaining life is found to affect yields, since the expected trading costs to the marginal investor vary with the remaining life of the security. Similar results are reported by Nashikkar and Subrahmanyam (2007) for the U.S. corporate bond market; they estimate that a one standard deviation improvement in liquidity leads to a 8-11 basis points reduction in the non-default component of the yield spread. These results shed some light on the term structure dimension of liquidity effects in this market.

The coefficients of the exogenous variables in the two equations provide important information about the common determinants of price and liquidity in this market. Higher spot rates are generally associated with higher excess implied volatility, implying that when there are inflation concerns and expectations of rising interest rates, the dealers charge even higher prices (and wider bid-ask spreads) for selling these options. Note that these options are all nearly ATM; therefore their pricing is not confounded by any smile effects that may be observed in this market. Once the effects of the spot rate are accounted for, the slope of the yield curve has a less significant effect on the EIV. The impact of increasing interest rate uncertainty is similar - when swaption volatilities are higher, the excess implied volatilities are also higher. When there is more uncertainty in fixed income markets, dealers appear to charge even higher prices (and wider bid-ask spreads) for these options. This increase in uncertainty worsens the basis risk and the model risk that dealers face, which, in turn, adversely affects liquidity, thereby increasing the slope of their supply curve, leading to higher prices and wider bid-ask spreads. Aggregate credit risk concerns, proxied by the default spread, do not appear to be significantly related to either price or liquidity in this market, except for longer maturity options. The futures volume on LIFFE is negatively 
related to the relative bid-ask spreads on caps and floors, indicating that the demand for hedging interest rate risk is one of the determinants of liquidity in the interest rate options markets. The CP/T-bill spread appears to be weakly related to the bid-ask spreads, since it is statistically significant at the $5 \%$ level only for some of the maturities. Aggregate liquidity shocks to financial institutions might play some role in affecting the liquidity of interest rate options, but their role is not very significant, perhaps because the interest rate options business is not a significant proportion of their overall operations.

We use the single equation version of the Hausman test to examine whether the variables assumed to be exogenous in the system are, in fact, uncorrelated with the structural disturbances. We examine the issue for each equation, for each of the exogenous variables. For each exogenous variable individually, we adopt the following procedure. First, we estimate the parameters of the equation using two-stage least squares, treating the variable in question as an exogenous variable. Then we compute an instrumental variables estimate of the same parameters, where the instrumented values of the endogenous variables are estimated using the remaining exogenous variables, excluding the exogenous variable being examined. A Wald test based on the difference of these two estimators examines the null hypothesis that the variable in question is indeed exogenous. In addition, we compute a system-wide statistic for model specification based on the specification test in Greene (2000). This is a likelihood ratio test based on the residuals with respect to the exogenous variables computed using three-stage least squares (a full information estimator) versus those computed using OLS. If the likelihood ratio statistic is below the chi-square critical value (with degrees of freedom equal to the number of over-identifying restrictions), the model specification is not rejected.

The diagnostic tests for the validity of our model show that our overall model specification cannot be rejected. The system-wide likelihood ratio statistic is 1.44 , much below the critical value at the $5 \%$ level of 5.99. In addition, the Hausman tests for each exogenous variable result in chi-square statistics well below the critical value at the $5 \%$ level of 3.84 . Therefore, we cannot reject the null hypothesis that the variables assumed to be exogenous are indeed exogenous within the system.

We also test for weak instruments using the first stage F-statistic and critical cut-off values provided by Stock and Yogo (2004), based on Stock, Wright, and Yogo (2002). Our F-statistics are well above the 
critical values for all option maturities, thus rejecting the null hypothesis of weak instruments at the 5\% level. These tests give us confidence that our instruments are strong and valid, within the overall specification of the simultaneous equation model.

The results, so far, use the mid prices of ATM options to estimate their EIV. Therefore, positive values of c2 and d2 imply that wider bid-ask spreads are associated with higher mid-prices, controlling for other factors. However, in response to lower liquidity, do the dealers just increase their ask prices, keeping their bid prices the same (which would still result in higher mid prices)? Or is there any effect of illiquidity on the bid prices of these options as well? In order to understand this relationship between liquidity and option prices further, we re-estimate the simultaneous equation model separately using EIV computed from ask and bid prices. The results from this analysis are presented in table IV; to conserve space, we only report the coefficients of $\mathrm{c} 2$ and $\mathrm{d} 2$. (The size and significance of the other coefficients as well as the $\mathrm{R}^{2}$ of the regressions are similar to those in table III.). On the ask side, the coefficients are positive and significant for all option maturities, indicating that the ask prices are definitely higher in states of the world where the bid-ask spreads are wider. This is consistent with the hypothesis that the dealers charge higher prices for selling these options, when they are more illiquid. The results on the bid side are actually more interesting — the coefficients are positive and significant at $10 \%$ for all maturities, with significance at the $5 \%$ level for the longer maturity caps and floors. This shows that when there is less liquidity, the dealers are also willing to pay more for buying some of the caps/floors, especially the longer maturity options. This is consistent with the explanation that some part of the risk of options is unhedgeable, and hence the dealers are less willing to hold net short positions, especially in the longer maturity options. When there is less liquidity, the dealers are also willing to pay more to find a counterparty to reverse their sell-side trades than they are when there is more liquidity. Of course, since the dealers are net short in the aggregate, not all of them are able to reverse their sell-side trades.

For robustness, we re-estimate the simultaneous equation model for ATM options using the two alternative benchmark volatility measures - the historical standard deviation of log changes in forward rates, as well as the relevant implied volatility from the swaptions market. The excess implied volatilities are calculated in a similar manner, as the difference between the implied volatility of the cap/floor and the benchmark volatility. The results from these tests are presented in table V. In the interest of brevity, we 
only present the coefficients of interest, $\mathrm{c} 2$ and $\mathrm{d} 2$, since the other coefficients are of similar sign and significance as before. We again find that across all maturities, the coefficients of EIV and RelBAS are positive and statistically significant, indicating that these ATM options become more expensive when their liquidity reduces, and vice-versa. ${ }^{27}$

\section{B.2. $\quad$ Liquidity Effects in Options Across Strikes}

In this sub-section, we expand our analysis to options across all strikes. In order to properly control for smile effects, we introduce the skewness and excess kurtosis of the underlying interest rate distribution, interacted with LMR, in the simultaneous equation model as additional controls for the time-varying patterns of volatility smiles in these markets. Skewness and excess kurtosis are estimated on a rolling basis using the historical forward rates data from the most recent 66 days. Much of the volatility smile in options arises as a result of stochastic volatility, jumps in interest rates or both, which manifest themselves in the interest rate distribution as skewness and excess kurtosis. Therefore, controlling for the skewness and excess kurtosis at least partially controls for the daily variation in the volatility smile arising from stochastic volatility or jumps in interest rate. As before, we also have the asymmetric quadratic functional form of LMR as a control for the general shape of the volatility smile observed in these markets. Therefore, the model we estimate is as follows:

$$
\begin{aligned}
& E I V=c 1+c 2 * \operatorname{RelBAS}+c 3 * L M R+c 4 * L M R^{2}+c 5 *\left(1_{L M R<0} . L M R\right) \\
& +c 6 * \text { SwpnVol }+c 7 * \text { DefSprd }+c 8 * 6 \text { Mrate }+c 9 * \text { Slope } \\
& +c 10 * L M R * \text { Skew }+c 11 *|L M R| * \text { Kurt } \\
& \text { RelBAS }=d 1+d 2 * E I V+d 3 * L M R+d 4 * L M R^{2}+d 5 *\left(1_{L M R<0} . L M R\right) \\
& +d 6 * \text { SwpnVol }+d 7 * \text { DefSprd }+d 8 * \text { LiffeVol }+d 9 * \text { CpTbSprd }
\end{aligned}
$$

The skewness is interacted with LMR, as the effect of skewness on the smile is likely to be asymmetric and dependent on the moneyness of the option. Excess kurtosis is interacted with absolute LMR, as the effect of kurtosis on the smile is likely to be symmetric and higher for away-from-the-money options. We estimate this model for bid-, mid-, and ask-prices, for our primary measure of option expensiveness that

\footnotetext{
${ }^{27} \mathrm{We}$ did several further robustness checks on our results, by re-estimating these models for bid and ask prices separately, as well as by using different historical time windows for calculating the standard deviation based reference volatility. These results were similar, and are not reported in the paper, but are available directly from the authors.
} 
uses the panel GARCH based volatility as the benchmark. The results for this analysis are presented in table VI. Again, to conserve space, we again present only the coefficients of interest, $\mathrm{c} 2$ and $\mathrm{d} 2$, since the size and significance of the coefficients as well as the $\mathrm{R}^{2}$ are similar to those in table III. We find that, across all maturities, more illiquid options are more expensive. They have significantly higher mid and ask prices, while the results for bid prices are somewhat weak for the shorter maturity caps/floors. It is important to note that the liquidity effects that we observe in this sub-section are incremental to the general volatility smile that is observed in this market, controlling for the daily changes in the skewness and excess kurtosis in the underlying interest rate distribution, thereby controlling for at least some of the effects of stochastic volatility and jumps in interest rates. In addition, since these effects are also present in the bid prices of these options, at least for the longer maturity caps/floors, it is unlikely that they arise only due to an increase in the ask prices.

As a further robustness check for the liquidity effects across strikes, we re-estimate the simultaneous equation model in equation (3) using the historical standard deviation and swaption implied volatilities as benchmark. These results, presented in table VII, confirm our results for ATM options that more illiquid options are more expensive, controlling for other effects, regardless of the benchmark volatility used for estimating the excess implied volatilities.

\section{C. $\quad$ The Relationship between Changes in Liquidity and Changes in Option Prices}

To analyze the relationship between price and liquidity further, we re-estimate the simultaneous equation model using first differences for at-the-money options. If liquidity affects asset prices, then changes in liquidity should also change asset prices (Amihud et al. (1990)). In table VIII, we present the results of the simultaneous equation model, where daily changes in EIV and RelBAS are regressed on each other as well as on changes in LMR functions and macro-financial variables, as follows:

$$
\begin{aligned}
\Delta E I V=c 1+ & c 2 * \Delta R e l B A S+c 3 * \Delta L M R+c 4 * \Delta L M R^{2}+c 5 * \Delta\left(1_{L M R<0} . L M R\right)+ \\
& c 6 \Delta S w p n V o l+c 7 * \Delta D e f S p r d+c 8 * \Delta 6 \text { Mrate }+c 9 * \Delta \text { Slope } \\
\Delta R e l B A S= & d 1+d 2 * \Delta E I V+d 3 * \Delta L M R+d 4 * \Delta L M R^{2}+d 5 * \Delta\left(1_{L M R<0} . L M R\right)+ \\
& d 6 * \Delta S w p n V o l+d 7 * \Delta D e f S p r d+d 8 * \Delta L i f f e V o l+d 9 * \Delta C p T b S p r d
\end{aligned}
$$


This model explicitly tests for the relationship between daily changes in the price and the liquidity of options, as opposed to the relationship between the levels of these variables examined earlier. As before, we estimate this model for ATM options separately for each option maturity. The results in table VIII are similar to the ones reported in table III, although these models have lower explanatory power, which is not surprising since they are estimated based on daily changes. The daily change in EIV is positively associated with the daily change in RelBAS, controlling for changes in option-specific and macrofinancial variables. In addition, we find that positive shocks to the changes in uncertainty in the fixed income markets are associated with positive shocks to changes in both price and liquidity of these interest rate options, although these effects are weaker than those observed in the simultaneous equation model, in

levels, estimated in the previous subsection. The overall model specification and Hausman tests again confirm that our instruments are valid. In addition, consistent with our findings in the previous section, we find stronger effects on the ask side than on the bid side, though the coefficients $\mathrm{c} 2$ and $\mathrm{d} 2$ are positive in both cases. We also obtain similar results when we repeat the tests for options across all strike rates, and when we use the other measures of EIV, calculated using the alternative benchmark volatilities.

The analysis above helps us understand the joint determinants of price and liquidity in this market. It establishes clearly that illiquid OTC Euro interest rate caps and floors trade at higher prices than the liquid ones, controlling for other effects. This result, contrary to established wisdom, is nonetheless consistent with the market structure and forces of demand and supply in this OTC market.

\section{Concluding Remarks}

The liquidity of an asset has an important influence on its market price. In recent years, this influence has been analyzed extensively in the U.S. equity markets, and, to a lesser extent, in the U.S. Treasury, corporate bond, and some foreign exchange options markets. The results from all these markets indicate that illiquidity suppresses the price of an asset, resulting in a higher expected return.

In contrast to this work on the underlying stock and bond markets, there is very little work on the influence of liquidity in the derivatives markets, particularly the OTC interest rate derivatives markets. This gap is striking for three reasons. First, derivatives markets are an important segment of the global financial markets, and thus need to be taken into account in assessing the overall liquidity in financial 
markets. Second, the effect of liquidity on the prices of derivatives is, by no means, clear cut. With zero net supply, both the buyers and sellers of derivatives are exposed to its illiquidity. In addition, in the case of derivatives, it is not obvious whether, for the purpose of the pricing of liquidity, the marginal investor would be long or short. It would depend on the risk exposures and the hedging needs of either side. Thus, the prices of illiquid derivatives could be higher or lower, as compared to the prices of derivatives that are more liquid. Third, the interest rate derivatives market is an OTC market, with a structure quite different from exchanges, and with contracts that are generally more illiquid compared to many exchange traded contracts. Therefore, the inferences drawn from studies on the liquidity effects in exchange-traded contracts may not be readily extendable to OTC contracts.

The liquidity and the price of an asset are fundamentally endogenous variables. Therefore, we examine the liquidity effects in the OTC euro interest rate options markets within a simultaneous equation model that endogenizes both liquidity and price, thereby modeling liquidity both as a cause and an effect. Our results show that more illiquid interest rate options are more expensive, controlling for other determinants of liquidity and price. Thus, this result is in sharp contrast to earlier findings in the stock and bond markets and in some exchange-traded currency options markets. As our results indicate, the relationship between illiquidity and asset prices cannot be generalized based on evidence from just the exchangetraded stock and the bond markets.

Our results have important implications for the role of liquidity in the pricing of derivative instruments. It would be worthwhile to explore this effect in other derivatives markets and for derivative instruments other than options, to see if this influence is similar, especially in other market settings. It would also be interesting to focus on crisis periods, such as the aftermath of the Russian default in 1998 and the LTCM failure that followed thereafter, and the more recent crisis in the credit markets, to examine the issue of episodic liquidity in such an extreme scenario. A related question that has not been explored in the literature so far is the interplay between the liquidity effects in the underlying asset market versus the market for derivatives.

Another important direction for future research based on our results is the development of models where one could include these drivers of liquidity in the pricing kernel itself. Furthermore, since interest rate 
options are much harder to price, with large pricing and hedging errors in general, liquidity-adjusted models could provide better pricing and hedging. Given the enormous size of this market, there are systemic effects of mispricing and/or inaccurate hedging - understanding such liquidity effects can help reduce such systemic risks. We leave these questions for future research. 


\section{Appendix A: Implied Volatility in the Black Model for Caps and Floors}

The standard model used for dealer quotations for interest rate caps and floors is the Black (1976) model of pricing of options on futures and forward contracts. The model is a variant of the basic Black and Scholes (1973) option pricing model. Applied to the interest rate option context, the model assumes that interest rates are log-normally distributed and relates the price of a European call option $(C)$ and a put option $(P)$, at time 0 , on an interest rate forward rate agreement (FRA), to the underlying variables as follows: ${ }^{28}$

$$
\begin{aligned}
& C=\left[f N\left(d_{1}\right)-k N\left(d_{2}\right)\right] \times m \times B_{0, t+m} \\
& C=\left[k N\left(-d_{2}\right)-f N\left(-d_{1}\right)\right] \times m \times B_{0, t+m} \\
& d_{1}=\frac{\ln f / k+t \sigma^{2} / 2}{\sqrt{t} \sigma} \\
& d_{2}=d_{1}-\sqrt{t} \sigma
\end{aligned}
$$

where

$f=\quad$ forward interest rate for the period $t$ to $t+m$,

$\sigma=\quad$ annualized volatility of the forward interest rate $t$ on the maturity date,

$m=\quad$ maturity period of the underlying loan,

$t=\quad$ maturity date of the option,

$k=\quad$ strike rate of the option, and

$B_{0, t+m}=$ the zero bond price at time 0 , for the bond maturing at date $t+m$.

Of course, the key variable in the above equations, which is not observable, but about which market participants may have differing views, is the volatility. Given all other parameters, a price of an option can be inverted to obtain an implied volatility. Thus implied volatility is a manifestation of price of the option.

\footnotetext{
${ }^{28}$ This formula is also consistent with the model proposed by Brace, Gatarek and Musiela (1997) [BGM] and Miltersen et al. (1997), which is popular among practitioners. BGM derive the processes followed by market quoted rates within the HJM framework, and deduce the restrictions necessary to ensure that the distribution of market quoted rates of a given tenor under the risk-neutral forward measure is log-normal. With these restrictions, caplets of that tenor satisfy the Black (1976) formula for options on futures and forward contracts.
} 
An interest rate cap (floor) is a collection of caplets (floorlets). A caplet (floorlet), in turn, is a single European call (put) option on a reference interest rate, expiring on a specific date. Hence, a cap (floor) can be regarded as a portfolio of European call (put) options on interest rates, or equivalently, put (call) options on discount bonds. Typically, an interest rate cap is an agreement between a cap writer and a buyer (for example, a borrower) to limit the latter's floating interest payments to a specific level for a given period of time. The cap is structured on a specific reference rate (usually the three- or the six-month Libor (London Interbank Offer Rate) or Euribor (Euro Interbank Offer Rate)) at a predetermined strike level. The reference rate is reset at periodic intervals (usually three or six months). In a similar manner, an interest rate floor contract sets a minimum interest rate level for a floating rate lender. The cap and floor contracts are defined on a pre-specified principal amount. ${ }^{29}$

A caplet with maturity $t_{\mathrm{i}}$ and strike rate $k$ pays at date $t_{\mathrm{i}}$, an amount based on the difference between the rate $\left(r_{\mathrm{i}}\right)$ at time $t_{\mathrm{i}}$ and the strike rate, if this difference is positive, and zero otherwise. The amount paid is based on the notional amount and the reset period of the caplet and is paid on a discounted basis at time $t_{\mathrm{i}}$. The payoff of this caplet at date $t_{\mathrm{i}}$ on a notional principal of $€ \mathrm{~A}$ is:

$$
c_{t_{i}}=A\left(t_{i+1}-t_{i}\right) \max \left[\frac{r_{i}-k}{1+r_{i}\left(t_{i+1}-t_{i}\right)}, 0\right]
$$

The payoff from a floorlet can be described in a similar manner.

Since the interest rate over the first period is known, there is no caplet corresponding to the first period of the cap. For example, a two-year cap on the six-month Euribor rate, with four semiannual periods over its life, would consist of three caplets, the first one expiring in six months, and the last one in one year and six months. Thus, the underlying interest rate for the first period is the six-month Euribor rate on the date six months from initiating the cap contract.

Each caplet or floorlet has to be valued separately, using a valuation model such as the Black or BGM model in equation (A.1) (the same model that is generally used by the market for quotation purposes), with the price of the cap or floor being the sum of these prices. The volatilities used for each caplet or

\footnotetext{
${ }^{29}$ Interest rate caps and floors for various maturities and reference rates in all the major currencies are traded in the over-the-counter (OTC) markets. The most common reference rate is the three-month Libor for USD caps/floors, and the six-month Euribor in the euro markets.
} 
floorlet, which are generally different, across strike rates and maturities, are sometimes called spot

volatilities. The market quotation for interest rate caps and floors, however, is based on the same volatility for all the caplets in a particular cap (or the floorlets in a particular floor). In other words, the market price of a cap (or floor) can be derived by plugging in this constant volatility for all the component caplets (or floorlets) in the contract. This constant volatility is referred to as the flat volatility for the particular cap (or floor) and varies with the maturity of the contract. Since caps are portfolios of caplets, the implied flat volatilities of caps reflect some average of the implied spot volatilities of individual caplets.

\section{Appendix B: Implied Bid-Ask Spreads of LIFFE Options on Euribor Futures}

We use the data for options on 3-month Euribor futures from January 1999 to May 2001. These options are traded on LIFFE and are part of LIFFE's flagship Euro interest rate suite. For each trading day of the sample, the LIFFE options on Euribor futures data give us the expiration date, exercise price, volume, open interest, opening price, high price, low price, closing price, the closing price for the underlying interest rate, and the implied volatility. We apply the methodology suggested in Corwin and Schultz (2008) (henceforth CS) to the high, low and closing prices to infer the bid-ask spreads for these contracts. We restrict our sample to options for which the volume, the low price and the difference between the high and low price for the day are all positive. This ensures that the high and low prices we use are based on traded options, and hence are informative.

CS develop the methodology based on the assumption that the price of the asset under consideration follows a geometric Brownian motion. This allows them to express the ratio of the daily high and low prices and the ratio of the high and low prices over a two-day interval as a function of the daily volatility and the bid-ask spreads. They compare the daily high and low prices with the closing price of the previous trading day and make adjustments to account for the overnight volatility. Their procedure results in somewhat noisy estimates of bid-ask spreads, with the estimated spreads sometimes being negative. They set such negative numbers to zero and take the average over positive and zero bid-ask spreads.

The assumption of geometric Brownian motion is reasonably appropriate for stocks, but not for options. Thus, we cannot directly apply their methodology to our options data from LIFFE. To overcome this 
problem, we convert the option prices to the corresponding underlying prices using the implied volatility for each option and the Black (1976) model for options on futures. In particular, we use the following formulae for the price of call (c) and put (p) options on futures:

$$
\begin{aligned}
& c=e^{-r T}\left[F N\left(d_{1}\right)-K N\left(d_{2}\right)\right. \\
& p=e^{-r T}\left[K N\left(-d_{2}\right)-F N\left(-d_{1}\right)\right. \\
& d_{1}=\frac{\log (F / K)+\sigma^{2} T / 2}{\sigma \sqrt{T}} \\
& d_{2}=\frac{\log (F / K)-\sigma^{2} T / 2}{\sigma \sqrt{T}}
\end{aligned}
$$

where $\mathrm{F}$ is the price of the underlying futures contract, $\mathrm{K}$ is the exercise price, $\sigma$ is the implied volatility and $\mathrm{T}$ is time to expiry. We use one minus the futures price as the interest rate, $\mathrm{r}$.

Using this model, we convert the high and low option prices to high and low futures prices. We then apply the CS methodology to these high and low underlying futures prices, comparing the high and low prices over two-day trading periods for the same type of option (put / call) with the same exercise price and the same maturity. We make all the adjustments that CS make including correction for overnight volatility and setting the negative bid-ask spreads to zero. Once we get the bid-ask spreads for the underlying futures contracts, we estimate the bid and ask quotes for the underlying futures contracts by applying the bid-ask spreads to the average of the high and low prices. We then convert the estimated bid and ask quotes of the underlying futures contracts back to the bid and ask quotes of the option using the Black model described above. We calculate the percent bid-ask spread for the options for every valid pair of two consecutive trading days for the same option, and calculate the average across all such pairs. Using this methodology, the average bid-ask spread for these exchange traded options is $3.6 \%$.

We also apply the model in Roll (1984) to closing option prices to estimate the bid-ask spreads. This methodology does not assume any particular distribution for the price of the asset. Thus, we apply it directly to the option prices. In this model, if the dollar spread is $2 \mathrm{c}$, the first order autocovariance of the price changes is $-c^{2}$. We do not have a long enough time series for any option with the same maturity and 
same exercise price to calculate the autocovariance of price changes. However, following CS, we calculate the autocovariance, $\gamma$, for every three consecutive trading days as follows:

$$
\gamma_{i, t}=\left(P_{i, t}-P_{i, t-1}\right)\left(P_{i, t-1}-P_{i, t-2}\right)
$$

where " $\mathrm{i}$ " is an option (put or call) with a given exercise price and given expiration and $\mathrm{P}$ is the closing price of that option. Then, we calculate the dollar spread, $2 \mathrm{c}$ and the percentage spread $\mathrm{pc}$ as follows:

$$
\begin{aligned}
2 c_{i, t} & =2 \sqrt{-\min \left(\gamma_{i, t}, 0\right)} \\
p c_{i, t} & =\frac{2 c_{i, t}}{P_{i, t}}
\end{aligned}
$$

Just as the bid-ask spreads in the CS methodology can be negative, the autocovariance in this methodology can be positive. When that is the case, we set the autocovariance to zero. We take the average of the percentage bid-ask spread across all valid three-consecutive-trading-day periods across all options. As per this methodology, the average bid-ask spread for the exchange traded options is $11 \%$. 


\section{REFERENCES}

Amihud Y.. Illiquidity and stock returns: cross-section and time-series effects. Journal of Financial Markets 2002; 5; 31-56.

Amihud Y, Mendelson H.. Asset pricing and the bid-ask spread. Journal of Financial Economics 1986; $17 ; 223-249$.

Amihud Y, Mendelson H. Liquidity, maturity and the yields on U.S. government securities. Journal of Finance 1991; 46; 1411-1426.

Amihud Y, Mendelson H, Wood R. Liquidity and the 1987 stock market crash. Journal of Portfolio Management 1990; 6; 65-69.

Black F. The pricing of commodity contracts. Journal of Financial Economics 1976; 3; 167-179.

Black F, Scholes M. The pricing of options and corporate liabilities. Journal of Political Economy 1973; $81 ; 637-654$.

Bollen N P;Whaley R E. Does net buying pressure affect the shape of the implied volatility functions? Journal of Finance 2004; 59; 711-753.

Bollerslev T. Generalized autoregressive conditional heteroskedasticity. Journal of Econometrics 1986; $31 ; 307-327$.

Bongaerts D, De Jong, F, Driessen J. Derivative Pricing with Liquidity Risk: Theory and Evidence from the Credit Default Swap Market, Working Paper 2009 Erasmus University Rotterdam.

Brace, A; Gatarek, D, Musiela M. The market model of interest rate dynamics. Mathematical Finance $1997 ; 7 ; 127-155$.

Brenner M., Eldor R, Hauser S. The price of options illiquidity. Journal of Finance 2001; 56; 789-805.

Brenner R H., Harjes R H, Kroner K F. Another look at models of the short-term interest rate. Journal of Financial and Quantitative Analysis 1996; 3;, 85-107.

Brunnermeier M K, Pedersen L H. Market liquidity and funding liquidity. Review of Financial Studies 2008 (forthcoming).

Canina L, Figlewski S. The informational content of implied volatility. Review of Financial Studies 1993; $6 ; 659-681$.

Cetin U, Jarrow R, Protter P, M Warachka. Pricing options in an extended Black Scholes economy with illiquidity: Theory and empirical evidence. Review of Financial Studies 2006;19; 493-529.

Constantinides G M. Transaction costs and the pricing of financial assets. Multinational Finance Journal 1997; 1; 93-99.

Corwin S A, Schultz P. A simple way to estimate bid-ask spreads from daily high and low prices. Working paper 2008; University of Notre Dame

Cox J C, Ingersoll J E, Ross S A. A theory of the term structure of interest rates. Econometrica 1985; 53; $385-408$

Cvsa V, Ritchken P. Pricing claims under GARCH-level dependent interest rate processes. Management Science 2001; 47; 1693-1711 
De Jong F, Driessen J. Liquidity risk premia in corporate bond markets. Working Paper 2007; University of Amsterdam

Duffie D, Garleanu N, Pedersen L H. Over-the-counter markets. Econometrica 2005; 73; 1815-1847

Elton E, Gruber M, Agrawal D, Mann C. Explaining the rate spread on corporate bonds. Journal of Finance 2001; 56; 247-277

Engle R F. Autoregressive conditional heteroscedasticity with estimates of the variance of United Kingdom inflation. Econometrica 1982; 50; 987-1008

Fan R, Gupta A ,Ritchken P. On pricing and hedging in the swaption market: How many factors really? Journal of Derivatives 2007; 15; 9-33

Figlewski S. Options arbitrage in imperfect markets. Journal of Finance 1989; 44; 1289-1311

Fleming M J. Measuring Treasury market liquidity. Economic Policy Review (Federal Reserve Bank of New York) 2003; 9; 83-108

Gallmeyer M, Hollifield B, Seppi D J. Demand discovery and asset pricing. Working Paper 2007; Carnegie Mellon University

Garleanu N, Pedersen L H, Poteshman A M. Demand-based option pricing. Review of Financial Studies 2008 (conditionally accepted)

Gatev E, Strahan P E. Banks' advantage in hedging liquidity risk: Theory and evidence from the commercial paper market. Journal of Finance 2006; 61; 867-892

George T J; Longstaff F A. Bid-ask spreads and trading activity in the S\&P 100 index options market. Journal of Financial and Quantitative Analysis 1993; 28; 381-397

Glosten L R, Jagannathan R, Runkle D E. On the relation between the expected value and the volatility of the nominal excess return on stocks. Journal of Finance 1993; 48; 1779-1801

Goldreich D, Hanke B, Nath P. The price of future liquidity: Time-varying liquidity in the US Treasury market. Review of Finance 2005; 9; 1-32

Greene W H 2000 Econometric analysis $4^{\text {th }}$ edition Macmillan

Gupta A, Singh A, Zebedee A. Liquidity in the pricing of syndicated loans. Journal of Financial Markets 2008; 11;339-376

Heath D, Jarrow R, Morton A. Bond pricing and the term structure of interest rates: A new methodology for contingent claims valuation. Econometrica 1992; 60; 77-105.

Jarrow R A, Protter P. Liquidity risk and option pricing theory Handbook of Financial Engineering 2005 ed J Birge and V Linetsky Elsevier (forthcoming)

Krishnamurthy A. The bond/old-bond spread. Journal of Financial Economics 2002; 66; 463-506

Liu J, Longstaff, F A. Losing money on arbitrages: optimal dynamic portfolio choice in markets with arbitrage opportunities. Review of Financial Studies 2004; 17; 611-641

Longstaff F A. How much can marketability affect security values? Journal of Finance 1995a; 50; 17671774 
Longstaff F A. Option pricing and the martingale restriction. Review of Financial Studies 1995b; 8; 10911124

Longstaff $\mathrm{F}$ A. Optimal portfolio choice and the valuation of illiquid securities. Review of Financial Studies 2001; 14; 407-431

Longstaff F A. The flight-to-liquidity premium in US Treasury bond prices. Journal of Business 2004; 77; $511-526$

Longstaff F A. Asset pricing in markets with illiquid assets. American Economic Review 2008; (forthcoming).

Longstaff F A, Mithal S, Neis E. Corporate yield spreads: default risk or liquidity? New evidence from the credit default swap market. Journal of Finance 2005; 60; 2213-2253

Longstaff F A, Schwartz E S. Interest rate volatility and the term structure: A two-factor general equilibrium model. Journal of Finance 1992; 47; 1259-1282

Nashikkar A; Subrahmanyam M G, Mahanti S. Liquidity and arbitrage in the market for credit risk. Working paper 2009, New York University

Mayhew S. Competition market structure and bid-ask spreads in stock option markets. Journal of Finance 2002; 57; 931-958

Miltersen K, Sandmann K, Sodermann D. Closed form solutions for term structure derivatives with lognormal interest rates. Journal of Finance 1997; 52; 409-430

Roll R. A simple implicit measure of the effective bid-ask spread in an efficient market. Journal of Finance 1984; 39; 1127-1139

Shleifer A, Vishny R W. The limits of arbitrage. Journal of Finance 1997; 52; 35-55

Vijh A M. Liquidity of the CBOE equity options. Journal of Finance 1990; 45; 1157-1179 


\section{Table I}

\section{Descriptive Statistics for Cap and Floor Prices}

This table presents descriptive statistics on OTC euro $(€)$ interest rate cap and floor prices, across maturities and strike rates, over the sample period from January 1999 to May 2001. The caps and floors are grouped together by moneyness into five categories. The moneyness for these options is expressed in terms of the Log Moneyness Ratio (LMR), defined as the log of the ratio of the par swap rate to the strike rate of the cap/floor. All prices are averages, reported in basis points, with the standard deviations of these prices in parenthesis.

\begin{tabular}{|c|c|c|c|c|c|c|c|c|c|c|}
\hline \multirow[t]{3}{*}{ Maturity } & \multicolumn{5}{|c|}{ Caps } & \multicolumn{5}{|c|}{ Floors } \\
\hline & $\begin{array}{l}\text { Deep } \\
\text { OTM }\end{array}$ & OTM & ATM & ITM & $\begin{array}{l}\text { Deep } \\
\text { ITM }\end{array}$ & $\begin{array}{l}\text { Deep } \\
\text { ITM }\end{array}$ & ITM & ATM & OTM & $\begin{array}{l}\text { Deep } \\
\text { OTM }\end{array}$ \\
\hline & $\begin{array}{l}\text { LMR } \\
<-0.3\end{array}$ & $\begin{array}{l}-0.3< \\
\text { LMR } \\
<-0.1\end{array}$ & $\begin{array}{l}-0.1< \\
\text { LMR } \\
<0.1\end{array}$ & $\begin{array}{l}0.1< \\
\text { LMR } \\
<0.3\end{array}$ & $\begin{array}{c}\text { LMR } \\
>0.3\end{array}$ & $\begin{array}{l}\mathrm{LMR} \\
<-0.3\end{array}$ & $\begin{array}{l}-0.3< \\
\text { LMR } \\
<-0.1\end{array}$ & $\begin{array}{l}-0.1< \\
\text { LMR } \\
<0.1\end{array}$ & $\begin{array}{l}0.1< \\
\text { LMR } \\
<0.3\end{array}$ & $\begin{array}{c}\text { LMR } \\
>0.3\end{array}$ \\
\hline 2-year & $\begin{array}{c}2.1 \\
(0.5)\end{array}$ & $\begin{array}{l}11.1 \\
(5.8)\end{array}$ & $\begin{array}{c}43.2 \\
(19.8)\end{array}$ & $\begin{array}{l}107.7 \\
(30.9)\end{array}$ & $\begin{array}{l}250.5 \\
(58.8)\end{array}$ & $\begin{array}{l}250.5 \\
(48.1)\end{array}$ & $\begin{array}{l}153.7 \\
(50.7)\end{array}$ & $\begin{array}{c}55.5 \\
(25.4)\end{array}$ & $\begin{array}{c}13.6 \\
(7.9)\end{array}$ & $\begin{array}{c}3.6 \\
(2.0)\end{array}$ \\
\hline 3 -year & $\begin{array}{c}10.7 \\
(10.0)\end{array}$ & $\begin{array}{c}37.7 \\
(20.0)\end{array}$ & $\begin{array}{c}91.9 \\
(33.8)\end{array}$ & $\begin{array}{l}209.6 \\
(52.3)\end{array}$ & $\begin{array}{c}481.3 \\
(133.4)\end{array}$ & $\begin{array}{c}529.1 \\
(114.2)\end{array}$ & $\begin{array}{l}285.3 \\
(74.7)\end{array}$ & $\begin{array}{l}111.3 \\
(44.6)\end{array}$ & $\begin{array}{c}32.7 \\
(18.0)\end{array}$ & $\begin{array}{c}6.9 \\
(4.6)\end{array}$ \\
\hline 4-year & $\begin{array}{c}22.3 \\
(12.5)\end{array}$ & $\begin{array}{c}72.6 \\
(32.2)\end{array}$ & $\begin{array}{l}152.7 \\
(49.7)\end{array}$ & $\begin{array}{l}311.3 \\
(78.3)\end{array}$ & $\begin{array}{c}674.4 \\
(193.1)\end{array}$ & $\begin{array}{c}728.3 \\
(138.7)\end{array}$ & $\begin{array}{l}406.4 \\
(98.9)\end{array}$ & $\begin{array}{l}176.1 \\
(64.8)\end{array}$ & $\begin{array}{c}62.1 \\
(27.8)\end{array}$ & $\begin{array}{l}12.0 \\
(7.9)\end{array}$ \\
\hline 5-year & $\begin{array}{c}42.7 \\
(16.3)\end{array}$ & $\begin{array}{l}119.4 \\
(48.6)\end{array}$ & $\begin{array}{l}221.7 \\
(67.2)\end{array}$ & $\begin{array}{l}409.1 \\
(95.4)\end{array}$ & $\begin{array}{c}872.3 \\
(252.2)\end{array}$ & $\begin{array}{c}910.8 \\
(161.2)\end{array}$ & $\begin{array}{c}519.5 \\
(122.5)\end{array}$ & $\begin{array}{l}244.7 \\
(84.5)\end{array}$ & $\begin{array}{c}94.3 \\
(35.2)\end{array}$ & $\begin{array}{c}19.2 \\
(13.9)\end{array}$ \\
\hline 6-year & $\begin{array}{c}66.9 \\
(20.2)\end{array}$ & $\begin{array}{l}163.7 \\
(64.4)\end{array}$ & $\begin{array}{l}286.6 \\
(84.6)\end{array}$ & $\begin{array}{c}507.9 \\
(109.5)\end{array}$ & $\begin{array}{l}1,006.6 \\
(257.4)\end{array}$ & $\begin{array}{l}1,093.1 \\
(173.2)\end{array}$ & $\begin{array}{c}663.8 \\
(133.1)\end{array}$ & $\begin{array}{c}323.7 \\
(101.9)\end{array}$ & $\begin{array}{l}128.6 \\
(43.5)\end{array}$ & $\begin{array}{c}27.2 \\
(18.7)\end{array}$ \\
\hline 7-year & $\begin{array}{c}93.7 \\
(25.4)\end{array}$ & $\begin{array}{l}210.9 \\
(82.2)\end{array}$ & $\begin{array}{l}355.8 \\
(99.3)\end{array}$ & $\begin{array}{c}610.8 \\
(125.3)\end{array}$ & $\begin{array}{l}1206.4 \\
(275.5)\end{array}$ & $\begin{array}{l}1,239.0 \\
(147.0)\end{array}$ & $\begin{array}{c}809.3 \\
(127.5)\end{array}$ & $\begin{array}{c}393.3 \\
(115.2)\end{array}$ & $\begin{array}{l}164.1 \\
(51.9)\end{array}$ & $\begin{array}{c}36.9 \\
(33.0)\end{array}$ \\
\hline 8-year & $\begin{array}{l}123.9 \\
(31.4)\end{array}$ & $\begin{array}{l}264.2 \\
(98.1)\end{array}$ & $\begin{array}{c}433.2 \\
(115.9)\end{array}$ & $\begin{array}{c}706.8 \\
(162.8)\end{array}$ & $\begin{array}{l}1,248.2 \\
(253.4)\end{array}$ & $\begin{array}{l}1,284.7 \\
(120.8)\end{array}$ & $\begin{array}{c}924.7 \\
(139.3)\end{array}$ & $\begin{array}{c}425.2 \\
(108.3)\end{array}$ & $\begin{array}{c}199.2 \\
(59.6)\end{array}$ & $\begin{array}{c}46.8 \\
(32.8)\end{array}$ \\
\hline 9-year & $\begin{array}{c}152.1 \\
(35.6)\end{array}$ & $\begin{array}{c}309.6 \\
(103.2)\end{array}$ & $\begin{array}{c}509.9 \\
(128.7)\end{array}$ & $\begin{array}{c}811.8 \\
(172.2)\end{array}$ & $\begin{array}{l}1,310.3 \\
(205.3)\end{array}$ & NA & $\begin{array}{c}997.1 \\
(150.2)\end{array}$ & $\begin{array}{c}482.3 \\
(120.9)\end{array}$ & $\begin{array}{l}235.0 \\
(69.6)\end{array}$ & $\begin{array}{c}58.9 \\
(41.5)\end{array}$ \\
\hline 10 -year & $\begin{array}{r}179.6 \\
(39.8)\end{array}$ & $\begin{array}{c}347.8 \\
(106.7)\end{array}$ & $\begin{array}{c}598.0 \\
(140.0)\end{array}$ & $\begin{array}{c}881.3 \\
(153.4)\end{array}$ & $\begin{array}{l}1,493.4 \\
(275.3)\end{array}$ & NA & $\begin{array}{l}815.5 \\
(31.1)\end{array}$ & $\begin{array}{c}541.7 \\
(139.6)\end{array}$ & $\begin{array}{l}242.9 \\
(61.9)\end{array}$ & $\begin{array}{c}71.3 \\
(50.1)\end{array}$ \\
\hline
\end{tabular}




\section{Table II}

\section{Relative Bid-Ask Spreads for Caps and Floors}

This table presents summary statistics on the bid-ask spreads for OTC euro $(€)$ interest rate caps and floors, scaled by the average of the bid and ask prices for the options, across strike rates, for different maturities, expressed as percentages. The statistics are presented for the sample period from January 1999 to May 2001. The caps and floors are grouped together by moneyness into five categories. The moneyness for these options is expressed in terms of the Log Moneyness Ratio (LMR), defined as the log of the ratio of the par swap rate to the strike rate of the cap/floor. All the spreads are averages, with the standard deviations of the relative spreads in parentheses.

\begin{tabular}{|c|c|c|c|c|c|c|c|c|c|c|}
\hline \multirow[t]{3}{*}{ Maturity } & \multicolumn{5}{|c|}{ Caps } & \multicolumn{5}{|c|}{ Floors } \\
\hline & $\begin{array}{l}\text { Deep } \\
\text { OTM }\end{array}$ & OTM & ATM & ITM & $\begin{array}{l}\text { Deep } \\
\text { ITM }\end{array}$ & $\begin{array}{l}\text { Deep } \\
\text { ITM }\end{array}$ & ITM & ATM & OTM & $\begin{array}{l}\text { Deep } \\
\text { OTM }\end{array}$ \\
\hline & $\begin{array}{l}\text { LMR } \\
<-0.3\end{array}$ & $\begin{array}{l}-0.3< \\
\text { LMR } \\
<-0.1\end{array}$ & $\begin{array}{l}-0.1< \\
\text { LMR } \\
<0.1\end{array}$ & $\begin{array}{l}0.1< \\
\text { LMR } \\
<0.3\end{array}$ & $\begin{array}{l}\text { LMR } \\
>0.3\end{array}$ & $\begin{array}{l}\text { LMR } \\
<-0.3\end{array}$ & $\begin{array}{l}-0.3< \\
\text { LMR } \\
<-0.1\end{array}$ & $\begin{array}{l}-0.1< \\
\text { LMR } \\
<0.1\end{array}$ & $\begin{array}{l}0.1< \\
\text { LMR } \\
<0.3\end{array}$ & $\begin{array}{c}\text { LMR } \\
>0.3\end{array}$ \\
\hline 2-year & $\begin{array}{c}80.9 \% \\
(21.2 \%)\end{array}$ & $\begin{array}{c}32.4 \% \\
(14.3 \%)\end{array}$ & $\begin{array}{l}14.7 \% \\
(4.8 \%)\end{array}$ & $\begin{array}{c}7.1 \% \\
(2.4 \%)\end{array}$ & $\begin{array}{c}3.8 \% \\
(0.5 \%)\end{array}$ & $\begin{array}{c}2.5 \% \\
(1.3 \%)\end{array}$ & $\begin{array}{c}4.5 \% \\
(1.3 \%)\end{array}$ & $\begin{array}{l}13.3 \% \\
(7.9 \%)\end{array}$ & $\begin{array}{c}30.8 \% \\
(11.7 \%)\end{array}$ & $\begin{array}{c}77.2 \% \\
(24.1 \%)\end{array}$ \\
\hline 3-year & $\begin{array}{c}44.2 \% \\
(22.9 \%)\end{array}$ & $\begin{array}{l}19.0 \% \\
(5.7 \%)\end{array}$ & $\begin{array}{l}11.4 \% \\
(3.2 \%)\end{array}$ & $\begin{array}{c}7.0 \% \\
(2.5 \%)\end{array}$ & $\begin{array}{c}3.8 \% \\
(0.6 \%)\end{array}$ & $\begin{array}{c}2.9 \% \\
(1.1 \%)\end{array}$ & $\begin{array}{c}4.7 \% \\
(1.1 \%)\end{array}$ & $\begin{array}{l}11.2 \% \\
(6.1 \%)\end{array}$ & $\begin{array}{c}31.6 \% \\
(18.1 \%)\end{array}$ & $\begin{array}{c}72.0 \% \\
(25.2 \%)\end{array}$ \\
\hline 4-year & $\begin{array}{l}26.1 \% \\
(9.4 \%)\end{array}$ & $\begin{array}{l}14.4 \% \\
(4.7 \%)\end{array}$ & $\begin{array}{l}9.1 \% \\
(2.5 \%)\end{array}$ & $\begin{array}{c}6.2 \% \\
(2.2 \%)\end{array}$ & $\begin{array}{c}4.1 \% \\
(1.0 \%)\end{array}$ & $\begin{array}{c}2.9 \% \\
(1.0 \%)\end{array}$ & $\begin{array}{c}4.5 \% \\
(1.0 \%)\end{array}$ & $\begin{array}{c}8.4 \% \\
(2.5 \%)\end{array}$ & $\begin{array}{c}22.2 \% \\
(14.5 \%)\end{array}$ & $\begin{array}{c}59.9 \% \\
(28.7 \%)\end{array}$ \\
\hline 5-year & $\begin{array}{l}20.0 \% \\
(5.5 \%)\end{array}$ & $\begin{array}{l}12.6 \% \\
(3.9 \%)\end{array}$ & $\begin{array}{c}8.6 \% \\
(2.3 \%)\end{array}$ & $\begin{array}{c}6.1 \% \\
(2.1 \%)\end{array}$ & $\begin{array}{c}4.1 \% \\
(0.9 \%)\end{array}$ & $\begin{array}{c}3.1 \% \\
(1.0 \%)\end{array}$ & $\begin{array}{c}4.7 \% \\
(1.1 \%)\end{array}$ & $\begin{array}{l}8.2 \% \\
(2.3 \%)\end{array}$ & $\begin{array}{c}19.8 \% \\
(13.2 \%)\end{array}$ & $\begin{array}{c}59.5 \% \\
(27.4 \%)\end{array}$ \\
\hline 6-year & $\begin{array}{l}18.3 \% \\
(4.8 \%)\end{array}$ & $\begin{array}{l}12.1 \% \\
(3.6 \%)\end{array}$ & $\begin{array}{c}8.5 \% \\
(2.2 \%)\end{array}$ & $\begin{array}{c}5.7 \% \\
(1.4 \%)\end{array}$ & $\begin{array}{c}4.1 \% \\
(0.9 \%)\end{array}$ & $\begin{array}{c}3.3 \% \\
(0.9 \%)\end{array}$ & $\begin{array}{c}4.7 \% \\
(1.2 \%)\end{array}$ & $\begin{array}{c}7.9 \% \\
(2.0 \%)\end{array}$ & $\begin{array}{l}15.8 \% \\
(7.5 \%)\end{array}$ & $\begin{array}{c}50.2 \% \\
(24.6 \%)\end{array}$ \\
\hline 7-year & $\begin{array}{l}17.6 \% \\
(4.4 \%)\end{array}$ & $\begin{array}{l}11.5 \% \\
(3.4 \%)\end{array}$ & $\begin{array}{c}8.4 \% \\
(2.1 \%)\end{array}$ & $\begin{array}{c}5.5 \% \\
(1.3 \%)\end{array}$ & $\begin{array}{c}4.1 \% \\
(3.9 \%)\end{array}$ & $\begin{array}{c}3.4 \% \\
(0.9 \%)\end{array}$ & $\begin{array}{c}4.6 \% \\
(1.1 \%)\end{array}$ & $\begin{array}{c}7.8 \% \\
(1.9 \%)\end{array}$ & $\begin{array}{l}14.0 \% \\
(5.0 \%)\end{array}$ & $\begin{array}{c}45.3 \% \\
(24.6 \%)\end{array}$ \\
\hline 8 -year & $\begin{array}{l}17.1 \% \\
(3.8 \%)\end{array}$ & $\begin{array}{l}11.1 \% \\
(3.3 \%)\end{array}$ & $\begin{array}{c}8.3 \% \\
(2.0 \%)\end{array}$ & $\begin{array}{c}5.6 \% \\
(1.1 \%)\end{array}$ & $\begin{array}{c}4.0 \% \\
(0.3 \%)\end{array}$ & $\begin{array}{c}3.2 \% \\
(1.0 \%)\end{array}$ & $\begin{array}{c}4.5 \% \\
(1.1 \%)\end{array}$ & $\begin{array}{l}8.1 \% \\
(2.0 \%)\end{array}$ & $\begin{array}{l}14.0 \% \\
(5.1 \%)\end{array}$ & $\begin{array}{c}42.3 \% \\
(21.9 \%)\end{array}$ \\
\hline 9-year & $\begin{array}{l}17.1 \% \\
(3.4 \%)\end{array}$ & $\begin{array}{l}11.0 \% \\
(3.1 \%)\end{array}$ & $\begin{array}{c}8.3 \% \\
(1.9 \%)\end{array}$ & $\begin{array}{c}6.0 \% \\
(0.7 \%)\end{array}$ & $\begin{array}{c}4.2 \% \\
(0.3 \%)\end{array}$ & NA & $\begin{array}{c}4.8 \% \\
(1.0 \%)\end{array}$ & $\begin{array}{c}8.3 \% \\
(2.0 \%)\end{array}$ & $\begin{array}{l}14.0 \% \\
(5.2 \%)\end{array}$ & $\begin{array}{c}40.0 \% \\
(20.8 \%)\end{array}$ \\
\hline 10 -year & $\begin{array}{l}17.1 \% \\
(2.9 \%)\end{array}$ & $\begin{array}{l}11.2 \% \\
(3.0 \%)\end{array}$ & $\begin{array}{c}7.9 \% \\
(1.8 \%)\end{array}$ & $\begin{array}{c}6.2 \% \\
(0.6 \%)\end{array}$ & $\begin{array}{c}4.1 \% \\
(0.3 \%)\end{array}$ & NA & $\begin{array}{c}4.7 \% \\
(1.2 \%)\end{array}$ & $\begin{array}{c}8.1 \% \\
(2.2 \%)\end{array}$ & $\begin{array}{l}14.9 \% \\
(5.5 \%)\end{array}$ & $\begin{array}{c}38.6 \% \\
(20.6 \%)\end{array}$ \\
\hline
\end{tabular}




\section{Table III}

\section{Determinants of Excess Implied Volatility and Bid-Ask Spreads in ATM Caps and Floors}

This table presents the results for a simultaneous equation model, for near-the-money options with LMRs between 0.1 and 0.1 , where the excess implied volatility of OTC euro $(€)$ interest rate caps/floors and relative bid-ask spreads are determined endogenously as a function of each other and of other exogenous variables, for the sample period from April 1999 to May 2001.

$$
\begin{gathered}
\text { EIV }=c 1+c 2 * \text { RelBAS }+c 3 * L M R+c 4 * L M R^{2}+c 5 *\left(1_{L M R<0} . L M R\right)+ \\
c 6 \text { SwpnVol }+c 7 * \text { DefSprd }+c 8 * 6 M r a t e+c 9 * \text { Slope } \\
\text { RelBAS }=d 1+d 2 * \text { EIV }+d 3 * L M R+d 4 * L M R^{2}+d 5 *\left(1_{L M R<0} . L M R\right)+ \\
d 6 * \text { SwpnVol }+d 7 * \text { DefSprd }+d 8 * \text { LiffeVol }+d 9 * \text { CpTbSprd }
\end{gathered}
$$

EIV is the excess implied volatility of the mid-price of the cap/floor relative to the benchmark volatility estimated using a panel GARCH model on historical interest rates. RelBAS is the bid-ask spread scaled by the mid-price. LMR is the logarithm of the ratio of the swap rate to the strike rate of the option. 6Mrate is the six-month Euribor rate. Slope is the difference between the five-year and six-month Euribor rates. SwpnVol is the implied volatility of at-the-money swaption of comparable maturity. DefSprd is the difference between the six-month Euribor and the six-month Treasury rate. LiffeVol is the logarithm of the trading volume of three-month Euribor futures on the LIFFE. CpTbSprd is the spread between the three-month AA Financial Commercial Paper rate and the three-month T-bill rate. Only the coefficients of interest are presented in this table.

Panel A: EIV as the dependent variable

\begin{tabular}{lccccccc}
\hline Maturity & $\mathrm{c} 2$ & $\mathrm{c} 6$ & $\mathrm{c} 7$ & $\mathrm{c} 8$ & $\mathrm{c} 9$ & Obs & $\mathrm{R}^{2}$ \\
\hline 2-year & $0.24^{* *}$ & $0.43^{* *}$ & 0.00 & $1.45^{*}$ & 1.96 & 1100 & 0.19 \\
3-year & $0.28^{* *}$ & $0.58^{* *}$ & 0.00 & $0.54^{*}$ & $1.34^{* *}$ & 1392 & 0.22 \\
4-year & $0.52^{* *}$ & $1.28^{* *}$ & 0.04 & $0.87^{* *}$ & $0.48^{*}$ & 1448 & 0.24 \\
5-year & $0.50^{* *}$ & $0.52^{* *}$ & 0.08 & $0.35^{* *}$ & 0.01 & 1430 & 0.21 \\
6-year & $0.69^{* *}$ & $0.73^{* *}$ & 0.12 & $0.75^{* *}$ & $0.68^{*}$ & 1468 & 0.38 \\
7-year & $0.71^{* *}$ & $0.93^{*}$ & $0.22^{*}$ & $0.90^{* *}$ & -1.12 & 1386 & 0.26 \\
8-year & $0.78^{* *}$ & $0.91^{* *}$ & $0.18^{*}$ & $0.86^{* *}$ & 0.11 & 1237 & 0.22 \\
9-year & $0.48^{* *}$ & $0.81^{*}$ & $0.25^{*}$ & $0.84^{*}$ & 0.07 & 1202 & 0.31 \\
10-year & $0.71^{* *}$ & $0.43^{* *}$ & $0.56^{*}$ & $0.10^{*}$ & 0.14 & 887 & 0.31 \\
& & & & & & & \\
\hline
\end{tabular}

Panel B: RelBAS as the dependent variable

\begin{tabular}{lccccccc}
\hline \multicolumn{1}{c}{ Maturity } & $\mathrm{d} 2$ & $\mathrm{~d} 6$ & $\mathrm{~d} 7$ & $\mathrm{~d} 8$ & $\mathrm{~d} 9$ & Obs & $\mathrm{R}^{2}$ \\
\hline 2-year & $0.50^{* *}$ & $0.46^{*}$ & 0.00 & $-0.03^{*}$ & 0.25 & 1100 & 0.26 \\
3-year & $1.43^{* *}$ & $0.89^{* *}$ & 0.00 & $-0.02^{* *}$ & $0.19^{* *}$ & 1392 & 0.17 \\
4-year & $1.24^{* *}$ & $0.60^{* *}$ & 0.03 & $-0.10^{* *}$ & $0.31^{*}$ & 1448 & 0.22 \\
5-year & $1.19^{* *}$ & $0.63^{* *}$ & $0.06^{*}$ & $-0.20^{* *}$ & $0.44^{* *}$ & 1430 & 0.32 \\
6-year & $1.32^{* *}$ & $0.68^{* *}$ & $0.13^{* *}$ & $-0.42^{* *}$ & $0.71^{* *}$ & 1468 & 0.32 \\
7-year & $1.38^{* *}$ & $0.62^{* *}$ & $0.04^{*}$ & $-0.27^{* *}$ & $0.64^{*}$ & 1386 & 0.32 \\
8-year & $1.29^{* *}$ & $0.65^{* *}$ & $0.34^{* *}$ & $-0.60^{* *}$ & $0.76^{*}$ & 1237 & 0.32 \\
9-year & $1.41^{* *}$ & $0.45^{* *}$ & $0.37^{* *}$ & $-0.86^{* *}$ & $0.66^{* *}$ & 1202 & 0.42 \\
10-year & $1.46^{* *}$ & $0.32^{* *}$ & $0.64^{* *}$ & $-0.90^{* *}$ & $0.51^{* *}$ & 887 & 0.42 \\
\hline
\end{tabular}

** implies significance at the 5\% level; * implies significance at the $10 \%$ level. 


\section{Table IV}

\section{Bid and Ask Side Determinants of Liquidity and Price (ATM)}

This table presents the results for a simultaneous equation model, for near-the-money options with LMRs between 0.1 and 0.1 , estimated separately using bid and ask prices, where the excess implied volatility of OTC euro $(€)$ interest rate caps and floors and the relative bid-ask spreads are determined endogenously as a function of each other, and other exogenous variables, for the sample period from April 1999 to May 2001:

$$
\begin{aligned}
& E I V=c 1+c 2 * \operatorname{RelBAS}+c 3 * L M R+c 4 * L M R^{2}+c 5 *\left(1_{L M R<0} . L M R\right)+ \\
& \text { c6SwpnVol }+c 7 * \text { DefSprd }+c 8 * 6 \text { Mrate }+c 9 * \text { Slope } \\
& \text { RelBAS }=d 1+d 2 * E I V+d 3 * L M R+d 4 * L M R^{2}+d 5 *\left(1_{L M R<0 .} L M R\right)+ \\
& d 6 * \text { SwpnVol }+d 7 * \text { DefSprd }+d 8 * \text { LiffeVol }+d 9 * \text { CpTbSprd }
\end{aligned}
$$

EIV is the excess implied volatility of the bid or the ask price of the cap/floor relative to the benchmark volatility estimated using a panel GARCH model on historical interest rates. RelBAS is the bid-ask spread scaled by the midprice. LMR is the logarithm of the ratio of the swap rate to the strike rate of the option. 6Mrate is the six-month Euribor rate. Slope is the difference between the five-year and six-month Euribor rates. SwpnVol is the implied volatility of at-the-money swaption of comparable maturity. DefSprd is the difference between the six-month Euribor and the six-month Treasury rate. LiffeVol is the logarithm of the trading volume of three-month Euribor

\begin{tabular}{|c|c|c|c|c|}
\hline & $\mathrm{c} 2$ & $\mathrm{~d} 2$ & $\mathrm{c} 2$ & $\mathrm{~d} 2$ \\
\hline 2-year & $0.08 *$ & $0.18^{*}$ & $0.28 * *$ & $0.74 * *$ \\
\hline 3-year & $0.07 *$ & $0.21 *$ & $0.31 * *$ & $1.66^{* *}$ \\
\hline 4-year & $0.21 *$ & $0.17 *$ & $0.92 * *$ & $1.39 * *$ \\
\hline 5-year & $0.34^{*}$ & $0.54 * *$ & $0.71 * *$ & $1.58 * *$ \\
\hline 6-year & $0.41 * *$ & $0.43^{*}$ & $0.75 * *$ & $1.89 * *$ \\
\hline 7-year & $0.31 *$ & $0.71 *$ & $0.82 * *$ & $2.01 * *$ \\
\hline 8 -year & $0.33 * *$ & $1.22 * *$ & $0.91 * *$ & $1.54 * *$ \\
\hline 9-year & $0.22 * *$ & $0.67 * *$ & $0.65 * *$ & $1.79 * *$ \\
\hline 10 -year & $0.44 * *$ & $0.91 * *$ & $0.82 * *$ & $1.72 * *$ \\
\hline
\end{tabular}
futures on the LIFFE. CpTbSprd is the spread between the three-month AA Financial Commercial Paper rate and the three-month T-bill rate. Only the coefficients of interest are presented in this table.

Maturity

\footnotetext{
** implies significance at the 5\% level; * implies significance at the $10 \%$ level.
} 


\section{Table V}

\section{Determinants of Liquidity and Price Using Alternative Volatility Benchmarks (ATM)}

This table presents the results for a simultaneous equation model, for near-the-money options with LMRs between 0.1 and 0.1 , where the excess implied volatility of OTC euro $(€)$ interest rate caps and floors and the relative bid-ask spreads are determined endogenously as a function of each other and other exogenous variables, for the sample period from April 1999 to May 2001:

$$
\begin{aligned}
& E I V=c 1+c 2 * \operatorname{RelBAS}+c 3 * L M R+c 4 * L M R^{2}+c 5 *\left(1_{L M R<0} . L M R\right)+ \\
& \text { c6SwpnVol }+c 7 * \text { DefSprd }+c 8 * 6 \text { Mrate }+c 9 * \text { Slope } \\
& \text { RelBAS }=d 1+d 2 * E I V+d 3 * L M R+d 4 * L M R^{2}+d 5 *\left(1_{L M R<0} . L M R\right)+ \\
& d 6^{*} \text { SwpnVol }+d 7 * \text { DefSprd }+d 8 * \text { LiffeVol }+d 9 * \text { CpTbSprd }
\end{aligned}
$$

EIV is the implied volatility of the mid price of the cap/floor relative to the alternative benchmark volatilities (historical standard deviation of changes in log rates and swaption volatilities of comparable maturity). RelBAS is the bid-ask spread scaled by the mid-price. LMR is the logarithm of the ratio of the swap rate to the strike rate of the option. 6Mrate is the six-month Euribor rate. Slope is the difference between the five-year and six-month Euribor rates. SwpnVol is the implied volatility of at-the-money swaption of comparable maturity. DefSprd is the difference

\begin{tabular}{|c|c|c|c|c|}
\hline \multirow[t]{2}{*}{ Maturity } & \multicolumn{2}{|c|}{ Historical Standard Deviation } & \multicolumn{2}{|c|}{ Swaption Volatility } \\
\hline & $\mathrm{c} 2$ & $\mathrm{~d} 2$ & $\mathrm{c} 2$ & $\mathrm{~d} 2$ \\
\hline 2-year & $0.39 * *$ & $1.05 * *$ & $0.19 *$ & $0.44 * *$ \\
\hline 3-year & $0.41 * *$ & $1.56^{* *}$ & $0.22 * *$ & $0.99 * *$ \\
\hline 4-year & $0.55 * *$ & $1.91 * *$ & $0.31 * *$ & $1.05^{* *}$ \\
\hline 5-year & $0.68 * *$ & $2.05 * *$ & $0.52 * *$ & $1.51 * *$ \\
\hline 6-year & $0.74 * *$ & $1.77 * *$ & $0.45^{* *}$ & $1.24 * *$ \\
\hline 7-year & $0.61 * *$ & $2.15^{* *}$ & $0.61 * *$ & $1.33 * *$ \\
\hline 8-year & $0.79 * *$ & $2.08 * *$ & $0.44 * *$ & $1.28 * *$ \\
\hline 9-year & $0.81 * *$ & $1.64 * *$ & $0.57 * *$ & $1.69 * *$ \\
\hline 10-year & $0.83^{* *}$ & $1.79 * *$ & $0.63 * *$ & $1.42 * *$ \\
\hline
\end{tabular}
between the six-month Euribor and the six-month Treasury rate. LiffeVol is the logarithm of the trading volume of three-month Euribor futures on the LIFFE. CpTbSprd is the spread between the three-month AA Financial Commercial Paper rate and the three-month T-bill rate. Only the coefficients of interest are presented in this table.

\footnotetext{
** implies significance at the 5\% level; * implies significance at the $10 \%$ level.
} 


\section{Table VI}

\section{Determinants of Liquidity and Price Across Strikes}

This table presents the results for a simultaneous equation model estimated separately using bid, mid and ask prices across all available strikes, where the excess implied volatility of OTC euro $(€)$ interest rate caps and floors and the relative bid-ask spreads are determined endogenously as a function of each other and other exogenous variables, for the sample period from April 1999 to May 2001:

$$
\begin{aligned}
& \text { EIV }= c 1+c 2 * \text { RelBAS }+c 3 * L M R+c 4 * L M R^{2}+c 5 *\left(1_{L M R<0} . \text { LMR }\right)+c 6 * \text { SwpnVol } \\
&+c 7 * \text { DefSprd }+c 8 * 6 M r a t e+c 9 * \text { Slope }+c 10^{*} L M R^{*} \text { Skew }+c 11^{*} \mid \text { LMR } \mid * \text { Kurt } \\
& \text { RelBAS }=d 1+d 2 * \text { EIV }+d 3 * L M R+d 4 * L M R^{2}+d 5^{*}\left(1_{L M R<0} . L M R\right)+d 6 * \text { SwpnVol } \\
&+d 7 * \text { DefSprd }+d 8 * \text { LiffeVol }+d 9 * \text { CpTbSprd }
\end{aligned}
$$

EIV is the implied volatility of the bid or the ask price of the cap/floor relative to the benchmark volatility estimated using a panel GARCH model on historical interest rates. RelBAS is the bid-ask spread scaled by the mid-price. LMR is the logarithm of the ratio of the swap rate to the strike rate of the option. 6Mrate is the six-month Euribor rate. Slope is the difference between the five-year and six-month Euribor rates. SwpnVol is the implied volatility of at-the-money swaption of comparable maturity. DefSprd is the difference between the six-month Euribor and the six-month Treasury rate. Skew is the skewness of the historical distribution of interest rates. Kurt is the excess

\begin{tabular}{|c|c|c|c|c|c|c|}
\hline \multirow[t]{2}{*}{ Maturity } & \multicolumn{2}{|c|}{ Bid Prices } & \multicolumn{2}{|c|}{ Mid Prices } & \multicolumn{2}{|c|}{ Ask Prices } \\
\hline & c2 & $\mathrm{d} 2$ & c2 & $\mathrm{d} 2$ & c2 & $\mathrm{d} 2$ \\
\hline 2-year & 0.04 & 0.07 & $0.18^{*}$ & $0.92 *$ & $0.33 * *$ & $1.19^{* *}$ \\
\hline 3 -year & $0.09 *$ & 0.03 & $0.31 * *$ & $0.78^{*}$ & $0.61 * *$ & $1.75^{* *}$ \\
\hline 4-year & $0.13 *$ & $0.08^{*}$ & $0.54 * *$ & $1.07 * *$ & $0.54 * *$ & $1.22 * *$ \\
\hline 5-year & $0.10^{*}$ & $0.15^{*}$ & $0.21 * *$ & $0.99 * *$ & $0.78 * *$ & $1.49 * *$ \\
\hline 6-year & $0.22 *$ & $0.49 *$ & $0.46^{* *}$ & $1.22 * *$ & $1.02 * *$ & $1.85^{* *}$ \\
\hline 7-year & $0.25^{* *}$ & $1.03 * *$ & $0.55^{* *}$ & $1.10 * *$ & $0.91 * *$ & $2.42 * *$ \\
\hline 8-year & $0.19^{*}$ & $0.57 *$ & $0.63 * *$ & $1.45^{* *}$ & $0.76^{* *}$ & $1.66^{* *}$ \\
\hline 9-year & $0.29 * *$ & $0.89 * *$ & $0.72 * *$ & $1.51 * *$ & $0.82 * *$ & $2.34 * *$ \\
\hline 10 -year & $0.34 * *$ & $1.24 * *$ & $0.57 * *$ & $1.09 * *$ & $0.93 * *$ & $1.73 * *$ \\
\hline
\end{tabular}
kurtosis of the historical distribution of interest rates. LiffeVol is the logarithm of the trading volume of three-month Euribor futures on the LIFFE. CpTbSprd is the spread between the three-month AA Financial Commercial Paper rate and the three-month T-bill rate. Only the coefficients of interest are presented in this table.

\footnotetext{
** implies significance at the 5\% level; * implies significance at the $10 \%$ level.
} 


\section{Table VII}

\section{Determinants of Liquidity and Price Across Strikes Using Alternative Volatility Measures}

This table presents the results for a simultaneous equation model estimated separately using mid prices across all available strikes, where the excess implied volatility of OTC euro $(€)$ interest rate caps and floors and the relative bid-ask spreads are determined endogenously as a function of each other and other exogenous variables, for the sample period from April 1999 to May 2001:

$$
\begin{aligned}
& \text { EIV }= c 1+c 2 * \text { RelBAS }+c 3 * L M R+c 4 * L M R^{2}+c 5 *\left(1_{L M R<0} . L M R\right)+c 6 * \text { SwpnVol } \\
&+c 7 * \text { DefSprd }+c 8 * 6 M r a t e+c 9 * \text { Slope }+c 10^{*} L M R^{*} \text { Skew }+c 11^{*}|L M R| * K u r t \\
& \text { RelBAS }=d 1+d 2 * \text { EIV }+d 3 * L M R+d 4 * L M R^{2}+d 5 *\left(1_{L M R<0} . L M R\right)+d 6^{*} \text { SwpnVol } \\
&+d 7 * \text { DefSprd }+d 8 * \text { LiffeVol }+d 9 * \text { CpTbSprd }
\end{aligned}
$$

EIV is the implied volatility of the mid price of the cap/floor relative to the alternative benchmark volatilities (standard deviation of changes in log rates as well as swaption volatilities of comparable maturity). RelBAS is the bid-ask spread scaled by the mid-price. LMR is the logarithm of the ratio of the swap rate to the strike rate of the option. 6Mrate is the six-month Euribor rate. Slope is the difference between the five-year and six-month Euribor rates. SwpnVol is the implied volatility of at-the-money swaption of comparable maturity. DefSprd is the difference between the six-month Euribor and the six-month Treasury rate. Skew is the skewness of the historical distribution of interest rates. Kurt is the excess of the historical distribution of interest rates. LiffeVol is the logarithm of the

\begin{tabular}{|c|c|c|c|c|}
\hline \multirow[t]{2}{*}{ Maturity } & \multicolumn{2}{|c|}{ Historical Volatility } & \multicolumn{2}{|c|}{ Swaption Volatility } \\
\hline & $\mathrm{c} 2$ & $\mathrm{~d} 2$ & $\mathrm{c} 2$ & $\mathrm{~d} 2$ \\
\hline 2-year & $0.32 *$ & $0.88^{*}$ & $0.19 *$ & $0.49 *$ \\
\hline 3-year & $0.45^{* *}$ & $1.05^{* *}$ & $0.52 *$ & $0.78^{* *}$ \\
\hline 4-year & $0.61 * *$ & $1.31^{* *}$ & $0.44 * *$ & $1.55^{* *}$ \\
\hline 5 -year & $0.52 * *$ & $1.07 * *$ & $0.29 * *$ & $1.41^{* *}$ \\
\hline 6-year & $0.49 * *$ & $2.11 * *$ & $0.22 * *$ & $1.29 * *$ \\
\hline 7-year & $0.65^{* *}$ & $1.55^{* *}$ & $0.54 * *$ & $2.67 * *$ \\
\hline 8 -year & $0.79 * *$ & $1.71^{* *}$ & $0.65^{* *}$ & $2.51^{* *}$ \\
\hline 9-year & $0.68 * *$ & $2.03 * *$ & $0.27 * *$ & $2.13^{* *}$ \\
\hline 10-year & $0.72 * *$ & $1.48^{* *}$ & $0.33^{* *}$ & $1.45^{* *}$ \\
\hline
\end{tabular}
trading volume of three-month Euribor futures on the LIFFE. CpTbSprd is the spread between the three-month AA Financial Commercial Paper rate and the three-month T-bill rate. Only the coefficients of interest are presented in this table.

\footnotetext{
** implies significance at the 5\% level; * implies significance at the $10 \%$ level.
} 


\section{Table VIII}

\section{Determinants of Changes in Excess Implied Volatility and Bid-Ask Spreads (ATM)}

This table presents the results for a simultaneous equation model, for near-the-money options with LMRs between 0.1 and 0.1 , where daily changes in the excess implied volatility of OTC euro $(€)$ interest rate caps and floors and daily changes in the relative bid-ask spreads are determined endogenously as a function of each other and of changes in other exogenous variables, for the sample period from April 1999 to May 2001:

$$
\begin{aligned}
\Delta E I V=c 1+ & c 2 * \Delta \text { RelBAS }+c 3^{*} \Delta L M R+c 4 * \Delta L M R^{2}+c 5^{*} \Delta\left(1_{L M R<0} . L M R\right)+ \\
& c 6 \Delta S w p n V o l+c 7 * \Delta \text { DefSprd }+c 8^{*} \Delta 6 M r a t e+c 9 * \Delta S l o p e \\
\Delta R e l B A S= & d 1+d 2 * \Delta E I V+d 3^{*} \Delta L M R+d 4 * \Delta L M R^{2}+d 5^{*} \Delta\left(1_{L M R<0} . L M R\right)+ \\
& d 6^{*} \Delta S w p n V o l+d 7 * \Delta \text { DefSprd }+d 8^{*} \Delta \text { LiffeVol }+d 9 * \Delta C p T b S p r d
\end{aligned}
$$

EIV is the implied volatility of the mid-price of the cap/floor relative to the benchmark volatility estimated using a panel GARCH model on historical interest rates. RelBAS is the bid-ask spread scaled by the mid-price. LMR is the logarithm of the ratio of the swap rate to the strike rate of the option. 6Mrate is the six-month Euribor rate. Slope is the difference between the five-year and six-month Euribor rates. SwpnVol is the implied volatility of at-the-money swaption of comparable maturity. DefSprd is the difference between the six-month Euribor and the six-month Treasury rate. LiffeVol is the logarithm of the trading volume of three-month Euribor futures on the LIFFE. CpTbSprd is the spread between the three-month AA Financial Commercial Paper rate and the three-month T-bill rate. Only the coefficients of interest are presented in this table.

Panel A: Changes in EIV as the dependent variable

\begin{tabular}{llllllll}
\hline Maturity & $\mathrm{c} 2$ & $\mathrm{c} 6$ & $\mathrm{c} 7$ & $\mathrm{c} 8$ & $\mathrm{c} 9$ & Obs & $\mathrm{R}^{2}$ \\
\hline 2-year & $0.47^{*}$ & $0.59^{*}$ & 0.00 & -1.37 & $1.36^{*}$ & 1090 & 0.07 \\
3-year & $1.09^{*}$ & 8.40 & 0.01 & $-2.30^{*}$ & 1.03 & 1364 & 0.05 \\
4-year & $0.63^{*}$ & $0.87^{* *}$ & $0.07^{*}$ & $-4.55^{*}$ & 2.69 & 1439 & 0.06 \\
5-year & $0.93^{* *}$ & $1.04^{*}$ & 0.03 & $-3.79^{*}$ & 2.23 & 1404 & 0.07 \\
6-year & $1.80^{*}$ & $1.04^{*}$ & $0.02^{* *}$ & $-1.29^{*}$ & 3.48 & 1429 & 0.09 \\
7-year & $3.29^{* *}$ & 2.84 & $0.01^{*}$ & -3.68 & 4.77 & 1367 & 0.11 \\
8-year & $3.75^{*}$ & $5.14^{*}$ & 0.01 & $-0.81^{* *}$ & 1.55 & 1149 & 0.12 \\
9-year & $4.87^{*}$ & $4.11^{*}$ & 0.09 & $-6.47^{*}$ & -1.00 & 1112 & 0.14 \\
10-year & $2.87^{* *}$ & $3.92^{*}$ & 0.01 & $-1.11^{* *}$ & -3.16 & 886 & 0.09 \\
\hline
\end{tabular}

Panel B: Changes in RelBAS as the dependent variable

\begin{tabular}{llllllll}
\hline Maturity & $\mathrm{d} 2$ & $\mathrm{~d} 6$ & $\mathrm{~d} 7$ & $\mathrm{~d} 8$ & $\mathrm{~d} 9$ & Obs & $\mathrm{R}^{2}$ \\
\hline 2-year & 2.86 & $1.14^{* *}$ & 0.00 & -0.08 & 0.01 & 1090 & 0.03 \\
3-year & $2.84^{* *}$ & $0.08^{* *}$ & 0.00 & -0.03 & 0.05 & 1364 & 0.09 \\
4-year & $0.14^{* *}$ & $0.58^{*}$ & 0.07 & $-0.02^{*}$ & 0.01 & 1439 & 0.07 \\
5-year & $0.44^{*}$ & $0.82^{* *}$ & $0.03^{*}$ & $-0.02^{* *}$ & 0.00 & 1404 & 0.06 \\
6-year & $0.56^{*}$ & $0.76^{* *}$ & 0.03 & $-0.03^{* *}$ & -0.01 & 1429 & 0.06 \\
7-year & $1.65^{* *}$ & $0.98^{* *}$ & 0.08 & $-0.04^{* *}$ & -0.01 & 1367 & 0.09 \\
8-year & $0.22^{* *}$ & $1.34^{* *}$ & $0.03^{*}$ & $-0.02^{* *}$ & 0.00 & 1149 & 0.13 \\
9-year & $0.45^{* *}$ & $1.02^{* *}$ & $0.02^{*}$ & $-0.01^{* *}$ & 0.00 & 1112 & 0.13 \\
10-year & $0.12^{* *}$ & $0.88^{*}$ & 0.04 & $-0.01^{* *}$ & 0.00 & 886 & 0.12 \\
\hline
\end{tabular}

** implies significance at the $5 \%$ level; * implies significance at the $10 \%$ level. 
Panel A: Panel GARCH volatility as benchmark
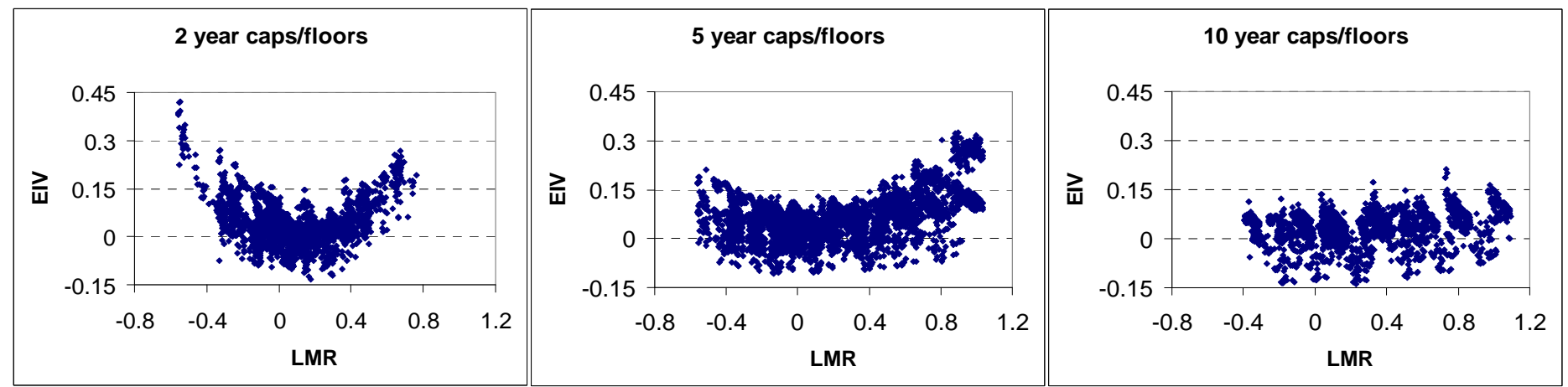

Panel B: Historical standard deviation as benchmark
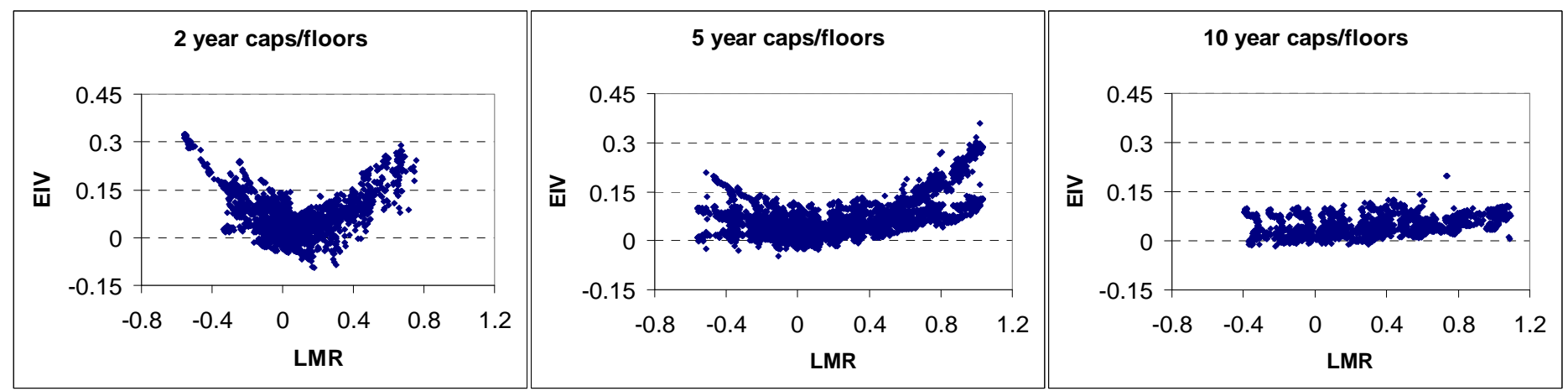

\section{Panel C: Swaption implied volatility as benchmark}
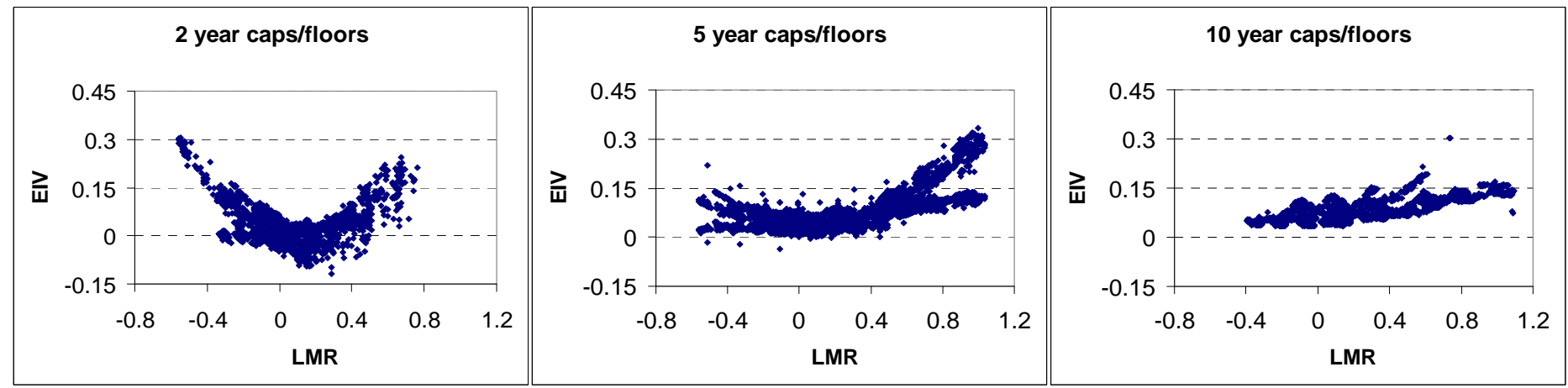

Figure 1. Volatility smiles using alternative benchmark volatilities. This figure presents scatter plots showing the shape of the volatility smiles for the excess implied flat volatilities of OTC euro (€) interest rate caps and floors, using three alternative benchmark volatilities - panel GARCH volatility, historical standard deviation and swaption implied volatility - over the sample period April 1999 to May 2001. The plots are presented for three representative maturities - two, five, and ten years. The plots for the other maturities are similar. 
Panel A: Panel GARCH volatility as benchmark
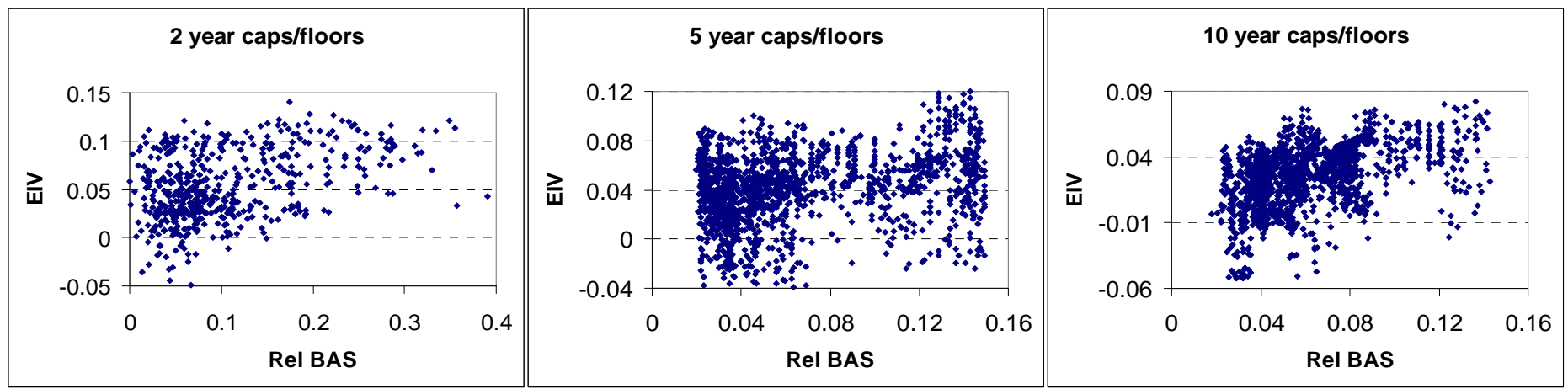

$\underline{\text { Panel B: Historical standard deviation as benchmark }}$
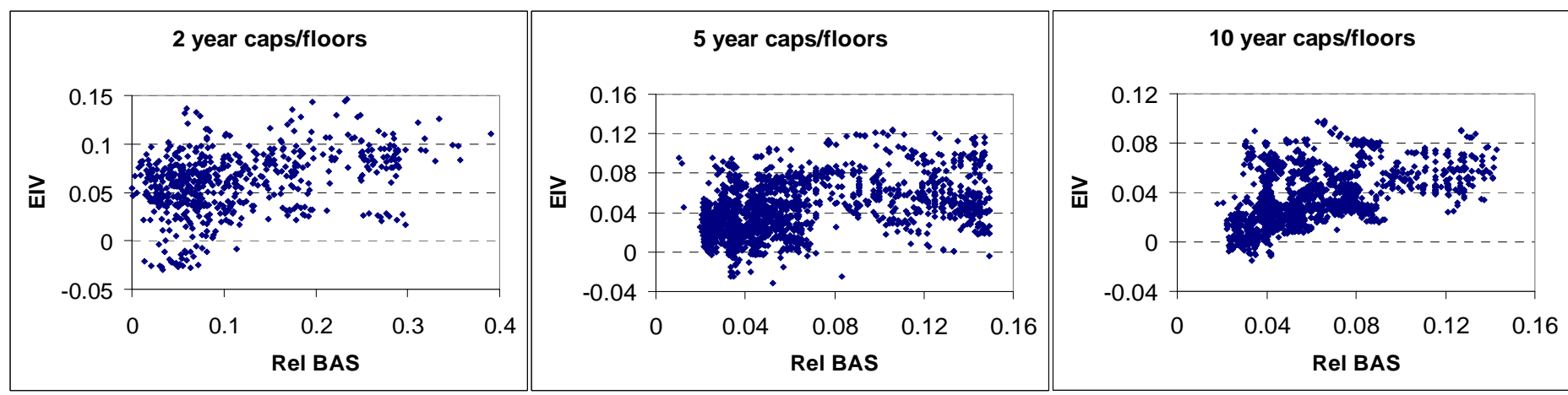

Panel C: Swaption implied volatility as benchmark
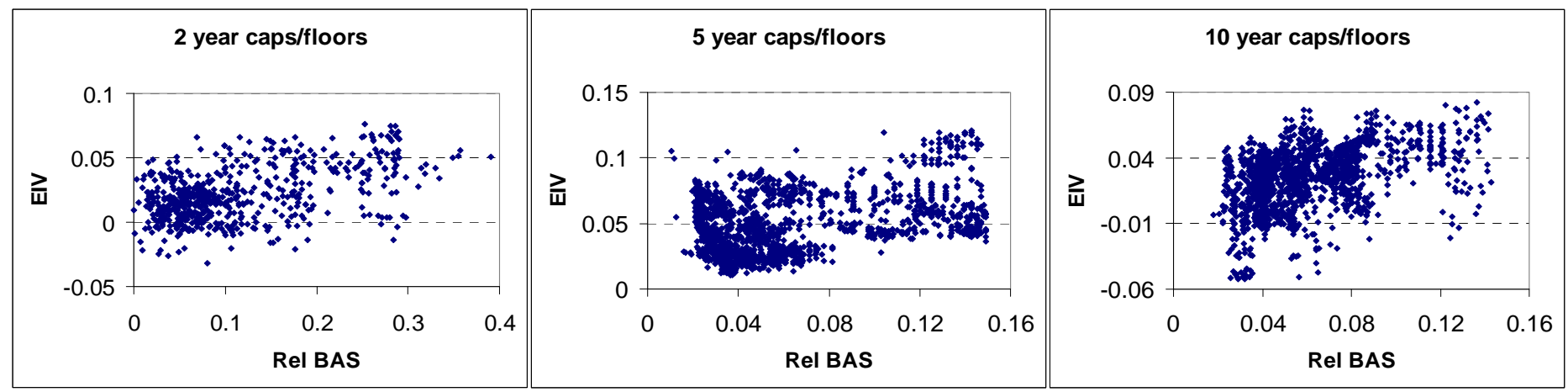

Figure 2. Plots of excess implied volatility versus liquidity. This figure presents three sample scatter plots of the excess implied volatility of euro $(€)$ interest rate caps and floors for the three benchmark volatilities - panel GARCH volatility, historical standard deviation and swaption implied volatility. The graphs show the relationship between the EIV and the RelBAS for two, five, and ten-year maturity caps and floors. The plots for other maturities are similar. The plots are constructed using data for OTC euro $(€)$ interest rate caps and floors over the sample period April 1999 to May 2001. 